\title{
A STUDY IN REGULATORY METHOD, LOCAL POLITICAL CULTURES, AND JURISPRUDENTIAL VOICE: THE APPLICATION OF FEDERAL CONFIDENTIALITY LAW TO PROJECT HEAD START
}

\author{
Richard C. Boldt*
}

\section{INTRODUCTION}

The problems associated with the abuse of alcohol and other drugs have reached into virtually every community in the United States. Even discounting for the rhetorical excess that characterizes some governmental pronouncements about drugs and alcohol, ${ }^{1}$ it seems clear that the compulsive use of addictive substances has had severe deleterious consequences for the lives of many individuals, their families, and their communities. Due to a confluence of factors, however, the corrosive effects of substance abuse have been experienced most acutely in the poorest communities, and have been borne disproportionately by the most vulnerable members of those communities, poor children. ${ }^{2}$

* Associate Professor of Law, University of Maryland. J.D. 1982, Yale; A.B. 1979, Columbia College. - Ed. I wish to thank Eileen Canfield and Marc Feldman for their valuable suggestions and unfailing support.

1. See, e.g., Office of Natl. Drug Control Policy, Executive Office of the President, National Drug Control Strategy 1 (1989); see also James A. Inctardi, The War on Drugs: Heroin, Cocaine, Crime, and Public Policy (1986).

2. See Raymond C. Collins \& Penny R. Anderson, U.S. Dept. of Health and Human Services, Head Start Substance Abuse Guide 3 (1991) (describing the finding of the 1990 National Household Survey on Drug Abuse, conducted for the National Institute on Drug Abuse, that the use of illegal drugs had increased among young adults, AfricanAmericans, the unemployed, and residents of large metropolitan areas).

It is important to distinguish between the harmful consequences of substance abuse itself and the harms indirectly associated with it, including violence between dealers, adulteration, HIV infection, abuse of children, and the like. In part, these harmful effects have been most pronounced in poor communities because of a preexisting economic vacuum. In addition, the vulnerability of many poor families due to inadequate housing, medical care, and educational services has only served to exacerbate the harms associated with alcoholism and drug addiction. Finally, the role of racism in the drug war should not be overlooked. See John A. Powell \& Eileen B. Hershenov, Hostage to the Drug War: The National Purse, the Constitution and the Black Community, 24 U.C. DAVrs L. REv. 557 (1991). For a compelling discussion of all these factors, see Kurt L. Schmoke, Testimony submitted to the U.S. Senate Committee on Governmental Affairs for a hearing on "Oversight of Federal Drug Policy Programs Affecting State and Local Government" (Oct. 13, 1989, on file with author); Legalization of Illicit Drugs: Impact and Feasibility, Part 1: Hearing Before House Select Comm. 
In the past few years, a number of "target cities" have received special funds from the Center For Substance Abuse Treatment (CSAT) of the Department of Health and Human Services, to improve the delivery of substance abuse treatment to needy populations. ${ }^{3}$ One of the most important CSAT Target Cities initiatives has been a program designed to encourage the development of programmatic linkages between substance abuse treatment resources and the local Head Start agencies in a given city. ${ }^{4}$ Baltimore, Maryland is among the cities that have received these special Head Start funds. 5

In 1991, the Baltimore Urban Services Agency, the Baltimore Target Cities grantee, began working with Baltimore City Head Start to develop a coordinated strategy for delivering substance abuse treatment and prevention services to the families comprising the city's Head Start population. ${ }^{6}$ Essential features of this project and others like it have included: the provision of early intervention and referral services for Head Start parents abusing alcohol or other drugs; the development of support programs for children from substance-abusing families; the creation of classroom-based strategies for staff members working with children who exhibit the physical and psychological effects of exposure to addicted adults; and the development of a family-centered case management system

on Narcotics Abuse and Control, 100th Cong., 2d Sess. 188-98 (1988) (testimony of Kurt L. Schmoke, Mayor of Baltimore).

3. The Target Cities Program began in the early 1990 s as a $\$ 28.5$ million undertaking. Its goal was to establish cooperative agreements with eight major cities to improve city-wide substance abuse treatment systems by developing partnerships to ensure the coordinated delivery of services. The program was originally started by CSAT's predecessor agency, The Office for Treatment Improvement (OTI). The first eight target cities were Albuquerque, Atlanta, Baltimore, Boston, Los Angeles, Milwaukee, New York, and San Juan. In addition, the Office for Substance Abuse Prevention (OSAP) of the Department of Health and Human Services awarded 95 demonstration grants under its Community Partnership Program to assist communities to plan and implement coordinated and comprehensive alcohol and drug abuse prevention programs. The Head Start Bureau of the Administration of Children and Families within HHS has been working in collaboration with both of these programs as part of its Substance Abuse Initiative. See Susan Weber, The Head Start Substance Abuse Initiative, NATL. HEAd START Bull, 1991, at 1.

4. Head Start is a federally funded program for poor children and their families. See 42 U.S.C. $\S \S 9831-9887$ (1988).

5. See Baltimore Urban Services Agency, Building the Capacity of Head Start Programs to Address the Issue of Substance Abuse (1991) (grant application, on file with author) [hereinafter Baltimore Urban Services Agency, Building the Capacity]; Baltimore Urban Services Agency, Collaboration Between Head Start Grantee and Target Cities Programs (1991) (grant application, on file with author) [hereinafter Baltimore Urban Services Agency, Collaboration].

6. Following the completion of a "needs assessment" and other background research into the incidence and effects of drug and alcohol abuse among Head Start families, the grantee developed the outlines for a comprehensive demonstration project. 
in which services directed to children and their substance-abusing parents are reinforced and coordinated in a "holistic" approach. ${ }^{7}$

Significantly, these projects have relied heavily upon Head Start personnel to perform diagnosis, referral, and counseling tasks in addition to providing the educational components of the plan. Indeed, not only did the Baltimore plan envision important roles for Head Start teachers, social workers, and parent liaisons, ${ }^{8}$ it also called for the hiring and training of special case managers responsible for the coordination of substance abuse treatment services offered to Head Start families. ${ }^{9}$

This article focuses on one particular set of issues raised by the effort to coordinate the activities of Head Start centers with those of substance abuse treatment programs and the introduction of treatment and prevention functions into the daily interactions of Head Start staff and parents. ${ }^{10}$ These issues involve the disclosure of potentially damaging information about a Head Start parent's drug or alcohol abuse and the confidentiality considerations that arise when she or he $\mathrm{e}^{11}$ has sought or received treatment for that abuse. Although it is possible to characterize these issues as technical, doctrinal questions of statutory and regulatory interpretation, it is also possible to understand them as questions of jurisprudential method that implicate the relationship between legal theory and practice. Stated simply, the problems arise because the system of statutes and administrative regulations governing the confidentiality of drug and alcohol treatment information assumes that treat-

7. Weber, supra note 3; see also SusAN WeBER ET AL, U.S. DePT. of HeAlth AND Human Services, Working With Substance Abusing Families (1994) (on file with author).

8. Parent liaisons are Head Start staff members whose responsibilities include working with parents both as "leamers" and as "decisionmakers." For a fuller discussion of the role of parents within Head Start, see infra text accompanying notes 48 and 49.

9. See Baltimore Urban Services Agency, Building the Capacity, supra note 5; see also Collins Management Consulting, Inc., Substance Abuse Related Needs Assessment of the Baltimore Head Start Program: Summary Findings (1991) (on file with author). The proposals that led to the funding of Baltimore's demonstration project included plans to grant priority access to Head Start services to children of parents in substance abuse treatment programs, as well as priority access to drug or alcohol treatment to the parents of children already enrolled in Head Start. Id. at 13.

10. Significantly, the planners of these cooperative undertakings have made clear that they are not developing alcohol and drug "treatment programs" within Head Start centers. Instead, the projects are described as substance-abuse-related services intended to support families with addiction problems "in the context of Head Start's basic child development goals." Weber, supra note 3, at 1; see also Collins \& ANDERSON, supra note 2, at 3.

11. The vast majority of Head Start parents are women. The Substance Abuse Initiative activities are directed not only to mothers involved in Head Start, however, but also to other family members with drug or alcohol problems who may have contact with Head Start children. 
ment programs will be structured as conventional social service agencies, but most Head Start centers are organized around, and deeply committed to, a very different set of institutional values. Thus, though the governing law with respect to confidentiality within the drug and alcohol abuse treatment system depends upon clear delineations between professionals and nonprofessionals, counselors and clients, individuals and families, the daily practices and operative premises of many Head Start centers reject these dichotomous categorizations and the values these distinctions express. ${ }^{12}$

This disjunction between legal premise and concrete reality causes law-practice problems, ${ }^{13}$ but it also provides an opportunity for an examination of regulatory methodology, the development of localized political culture, and issues of jurisprudential voice. The values expressed in the unusual organizational style of many Head Start programs reflect not only historical roots stretching back to the 1960s "war on poverty," but also the cumulative lived experience of the groups who have comprised Head Start both as staff and as recipients of services. Conventional legal assumptions and

12. See generally Lucie E. White, No Exit: Rethinking "Welfare Dependency" from a Different Ground, 81 GEO. L.J. 1961, 2001 (1993).

13. In the spring of 1992, I taught a course at the University of Maryland School of Law in which my first-year students engaged in field work representing drug and alcohol abuse treatment programs. Although most of the students in this course were assigned to work with individual drug and alcohol abuse treatment programs, one team of students spent the semester consulting with the Target Cities grantee in Baltimore. For a fuller description of this course, see Richard Boldt \& Marc Feldman, The Faces of Law In Theory and Practice: Doctrine, Rhetoric, and Social Context, 43 HAstings L.J. 1111 (1992).

Building upon an ongoing consulting relationship I had established with the Baltimore Target Cities grantee and other grantees around the country, the students assisted me in shaping the basic organizational structure of the Head Start Substance Abuse Initiative. This required that we balance the participants' need for a free flow of information against legal requirements that ordinarily restrict the communication of sensitive data about persons in substance abuse treatment.

The program had been designed with little input from lawyers knowledgeable about the statutes and regulations goveming the confidentiality of substance abuse treatment records. As soon as we became involved with the Baltimore project and the equivalent organizations in other grantee cities, we discovered that there were some very serious problems with their design. On the one hand, the laws and regulations that govern all federally assisted substance abuse treatment providers (including those who hold themselves out as providing diagnosis or referral) require that extremely strict safeguards be followed regarding the disclosure of patient-identifying information. See generally 42 U.S.C. $\$ \$ 290 d d-3,290 e-3$ (1988); 42 C.F.R. \$§ 2.1-2a.8 (1994). On the other hand, in order to facilitate coordination between Head Start programs and substance abuse treatment providers, information about parents' drug and alcohol abuse must be shared with teachers, parent liaisons, referral sources, and the like. Indeed, the central goal of the Substance Abuse Initiative was to foster the kind of collaborative family counseling that can only take place when confidential information is made available to a relatively wide array of persons. For a summary of the students' resolution of this tension, see Patricia Barker et al., Confidentiality of Substance Abuse Information: A Training Manual for Baltimore City Head Start (1992) (on file with author). 
structures have failed to address the needs of these communities. The application of the confidentiality laws and regulations to the substance-abuse-related activities of Head Start exemplifies the shortcomings of the current legal system. Too often the interests of historically subordinated groups have been ill-served by traditional institutional structures and correspondingly traditional forms of legal analysis. Thus, it is appropriate to employ a different form of methodology, both to illuminate the situated and partial nature of legal prescriptions generally and to provide one example of how the use of an alternative jurisprudence may hold the potential for making the law more responsive to women, children, the poor, and people of color.

Part I of this article sets out the statutory and regulatory scheme that governs the confidentiality accorded to drug and alcohol abuse treatment information. Accompanying that discussion is an examination of the societal interests generally thought to be served by these laws, as well as an exploration of their applicability to Head Start centers engaged in the kind of coordinated efforts envisioned by the Target Cities program. Part II provides more information about Head Start itself and includes an abbreviated political and social history focusing on a tradition of parental involvement in staffing and governance. An appreciation of this counterethic of client participation and governance is essential to an understanding of what makes Head Start distinctive. Elaboration of this local culture and organizational style will clarify the clash between legal regulation governing confidentiality and the everyday practice of Head Start.

Part III, in turn, provides a series of alternative lenses through which to analyze the questions of confidentiality Head Start's efforts to provide substance abuse-related services raises. These alternative accounts reveal the partial perspective embedded within the relevant confidentiality statutes and regulations and suggest other perspectives that policymakers, administrators, and others might adopt. Each alternative lens draws upon a literature that has, in some fashion, offered a critique of traditional forms of law. The first lens draws on a body of work that includes a critique of the individualistic, rights-based approach of liberal legalism. The second lens utilizes feminist scholarship that puts forward both an alternative jurisprudential methodology and an alternative account of social relationships. The third and final lens comes from the work of a group of scholars of color who offer a vision of law centered upon experiences of exclusion and subordination. 


\section{The Doctrinal Landscape: Confidentiality of Drug and AlCOHOl Abuse Treatment INFormation}

\section{A. The Federal Statutes and Regulations}

In the early 1970s, Congress passed two statutes designed to ensure the strict confidentiality of information about persons seeking or receiving treatment for drug or alcohol abuse. ${ }^{14}$ Pursuant to this Congressional mandate, in 1975 the Department of Health, Education, and Welfare promulgated regulations intended to clarify the obligations of treatment programs with respect to patient confidentiality and to operationalize the general statutory prohibition against disclosure..$^{15}$ In 1987, the Department of Health, Education, and Welfare's successor, the Department of Health and Human Services (HHS), issued a revised set of confidentiality regulations that currently apply to all federally assisted substance-abuse treatment programs. ${ }^{16}$

The authors of the original federal regulations specified two policy objectives of the general prohibition against disclosure; both the enabling legislation and the regulations articulate these objectives. The first is a concept long associated with the testimonial privileges attaching to doctor-patient, lawyer-client, and priest-penitent relationships: the notion that protecting an individual's privacy will encourage openness and trust. ${ }^{17}$ The drafters of the federal regulations also identified a more unusual objective animating the law in this area: the idea was that if all treatment providers adhered to a comprehensive and rigorous confidentiality scheme, it would

14. The provision relating to the confidentiality of drug treatment information was initially passed as $\S 408$ of the Drug Abuse Office and Treatment Act of 1972, Pub. L. No. $92-$ 255,86 Stat. 65,79 (codified as amended at 21 U.S.C. $\$ 1175$ (1982)). That section was transferred and amended by Pub. L. 98-24 to $\$ 527$ of the Public Health Service Act, codified at 42 U.S.C. \& 290ee-3 (1988 \& Supp. V 1993). A similar process led to the codification of an identical provision relating to the confidentiality of alcohol abuse treatment information at 42 U.S.C. $\S 290$ dd-3 (1988 \& Supp. V 1993). Both statutes were amended in 1986 to allow treatment providers to comply, at least in part, with state law obligations to report child abuse and neglect. Children's Justice and Assistance Act of 1986, Pub. L. No. 99-401, \& 106, 100 Stat. 906 (1986) (amending sections 523(e) and 527(e) of the Public Health Service Act, 42 U.S.C. $\$ \S 290$ dd-3(e), 290ee-3(e)). In 1992, Congress consolidated the two confidentiality statutes into a single provision governing both alcohol and drug abuse treatment records. 42 U.S.C. \& 290dd-2 (Supp. IV 1992). As this consolidation did not involve any substantive changes, the implementing regulations were not revised.

15. Public Health Service, Department of Health, Education, and Welfare, Confidentiality of Alcohol and Drug Abuse Patient Records, 42 C.F.R. $\$ \S 2.1$ to 2.67-1 (1975).

16. Public Health Services, Department of Health and Human Services, Confidentiality of Alcohol and Drug Abuse Patient Records, 42 C.F.R. $\$ \$ 2.1$ to 2.67 (1987).

17. 42 C.F.R. $\$ 2.4$ (1975). On testimonial privileges generally, see Rignal W. Baldwin, Confidentiality Between Physician and Patient, 22 MD. L. REv. 181 (1962); Fred L. Kuhlmann, Communications to Clergymen - When Are They Privileged?, 2 VAL. U. L. REv. 265 (1968), 
help to create a perception "on the street" that it is safe to seek treatment for the highly stigmatized conditions of alcoholism and drug addiction. 18

In keeping with these strongly articulated policy objectives, the federal confidentiality laws and regulations operate around a general prohibition against disclosure. ${ }^{19}$ Unless one of a limited number of exceptions applies, the general rule is that a federally assisted drug or alcohol treatment program may not disclose any information that would identify a person as a patient who has sought or received substance abuse treatment.

The broad definitions of key terms convey just how expansive the prohibition on disclosure is. The regulations define a "program" as "a person which, in whole or in part, holds itself out as providing, and provides, alcohol or drug abuse diagnosis, treatment, or referral for treatment." 20 Further, the regulations define a "disclosure" as a "communication of patient identifying information," whether it is oral or in writing, and even if the recipient already has the information conveyed. ${ }^{21}$ Strikingly, the term "patient" includes any person who has applied for or received an interview, counseling, or any other related service by a treatment program, even if the

18. 42 C.F.R. $\$ 2.4$ (1975). Attention to both of these goals is necessary in order to appreciate how the confidentiality regulations operate. Unlike analogous common law or statutory privileges present in most states that focus upon disclosures in the course of litigation or other formal proceedings, see, e.g., MD. CouRTs AND JUD. PROC. § 9-109(b) (1975), the federal restrictions apply to the communication of information about substance-abuse patients in virtually any setting. See 42 C.F.R. $\$ 2.11$ (1987) (defining "disclosure"). Moreover, the protections the federal laws and regulations afford are neither held simply by the patient nor limited to her direct control. Instead, because of the overarching goal of promoting a systemwide adherence to strict confidentiality, the regulations generally regard the treatment program as a rights holder presenting interests of equal moment to those of the individual patient. 42 C.F.R. $\$ 2.33$ (1987). Significantly, in subpart E of the regulations, which governs court orders for the disclosure of drug or alcohol abuse treatment information, a judge is required to make a finding of "good cause" before she is empowered to issue an order. In determining whether "good cause" exists, the judge is directed to give weight to the interests of the "treatment system" in maintaining patient confidentiality. 42 C.F.R. $\$ \S 2.61-.67$ (1987).

19. 42 C.F.R. $\S \S 2.12,2.13(\mathrm{a})$ (1994).

20. 42 C.F.R. $\S 2.11$ (1987). The 1987 amendments to the regulations changed this definition to make clear that an entity will not be considered a "program" unless it "holds itself out" as providing substance abuse-related services. 42 C.F.R. \& 2.11 (1987). In addition, the amended regulations added a special provision that limits their application to specialized personnel within a general hospital or community mental health center. 42 C.F.R. $\S 2.11$ (1987).

A program is "federally assisted" within the meaning of the federal laws and regulations if it receives federal funds in any form, has a grant of tax-exempt status from the Internal Revenue Service, is licensed by the federal government, or is conducted directly by the federal government. 42 C.F.R \& 2.12 (1994).

21. 42 C.F.R. $\S 2.11$ (1994). 
individual has never been admitted for treatment and even if the program deemed that she was not in need of such services.22

The regulations do provide a limited number of exceptions to the general rule to assist treatment program personnel faced with the choice to disclose or withhold information. Several of these exceptions emerge from the basic definitions set out above. In order for a communication of information to be a "disclosure" and therefore subject to the federal prohibition, it must identify a person as a "patient." Thus, a communication that is anonymous in the sense that it does not contain the patient's name, address, social security number, or likeness; that does not link an individual to drug or alcohol abuse treatment, which may be possible when the program speaks through an "umbrella" agency such as a general hospital, county public health department, or other multiple service provider; or that appears in the form of aggregate data is not prohibited. 23

Similarly, a communication of information, even if it identifies a patient, is not a prohibited disclosure if it occurs within a "program" in which the recipient has a need for the information in connection with her provision of treatment services to the patient. ${ }^{24}$ Other exceptions exist for patient-identifying disclosures in cases of "medical emergency," 25 when a crime has been threatened or committed against program staff or on program premises, ${ }^{26}$ when a staff

22. 42 C.F.R. $\S \S 2.11,2.15$ (b) (1994). The following hypothetical illustrates the breadth of these provisions, when taken together. Assume a school-based prevention program of the kind that is becoming increasingly common in many communities. Clearly, when a substance abuse counselor addresses a group of junior high school students at an assembly, the students are not "patients" whose identity or participation is subject to the general prohibition against disclosure. If one of the children were to approach the counselor after the group meeting and discuss her or his use of alcohol or request information about available treatment resources, however, that student would be a "patient" whose confidentiality would be protected by the federal laws and regulations. The key factor here is that once an individualized interaction has taken place in which a staff member of a "program" has engaged in counseling, diagnosis, or referral activities, the law applies. This is true even if the counselor in the hypothetical concludes that the student does not have a problem and is not in need of any services, because that conclusion would be deemed by the regulations to be a diagnosis or assessment which falls within the broad definition of "treatment." 42 C.F.R. $\$ 2.11$ (1994).

23. 42 C.F.R. $\S 2.11$ (1994).

24. 42 C.F.R. $\$ 2.12$ (c)(3) (1994). In addition, the regulations allow treatment programs to communicate with an outside entity providing needed services if the outside entity enters into a "qualified service organization" agreement in which it agrees to treat any patientidentifying information it receives with full confidentiality. Essentially, this sort of an agreement brings the outside service provider into the program, thus converting the disclosure into an internal communication. 42 C.F.R. $\$ 2.11$ (1994).

25. 42 C.F.R. $\$ 2.51$ (1994). This exception is limited to extremely serious circumstances, and only "medical personnel" may receive patient-identifying information.

26. 42 C.F.R. \& 2.12(c) (1994). In these cases, only "law enforcement personnel" may be contacted. 
member of the program suspects that a patient is engaged in child abuse or neglect, ${ }^{27}$ or when a court has issued a proper court order. ${ }^{28}$

The most common exception applies to cases in which the patient has given her consent to a disclosure. The consent provisions of the federal regulations ${ }^{29}$ differ from state rules regarding waiver of testimonial privileges in that a patient's consent to disclosure of drug or alcohol abuse information empowers, but does not compel, such a communication by a treatment program. ${ }^{30}$ Additionally, the federal regulations' treatment of patient consent differs from other more familiar waiver provisions, such as consent for the release of general medical records, in their administrative complexity and inherently parsimonious approach to the sharing of information. In order for consent to be effective, it must be given in writing and must meet an extensive list of criteria. Not only must the written permission contain the name of the patient, the treatment program, and the recipient of information, it must also contain a statement of the purpose for the proposed disclosure, a description of the precise information to be communicated, an identification of the "date, event, or condition upon which the consent will expire," and a statement that the consent is subject to revocation by the patient at any time unless the program has already acted in reliance on it. ${ }^{31}$ Finally, with every disclosure made by a substance-abuse treatment program pursuant to a patient's consent, the regulations require that a written notice prohibiting redisclosure be forwarded to the recipient of the information. ${ }^{32}$

27. 42 C.F.R. § 2.12(c) (1994).

28. 42 C.F.R. $\$ \S 2.61-67$ (1994). Before an order may issue, the court must give notice to the patient and the treatment program, must follow elaborate procedures, must find "good cause" for the information to be disclosed, and must limit the disclosure accordingly. 42 C.F.R. $\S \S 2.61-.67$ (1994). These procedural and substantive requirements mean that this sort of an order is quite different, and more difficult to obtain, than other, more familiar, compulsory processes such as warrants and subpoenas.

29. 42 C.F.R. $\S \S 2.31-.35$ (1994).

30. The only significant exception is when the patient's consent is accompanied by some other compulsory process, such as a judicial subpoena. In these cases, the consent removes any federal law prohibition against disclosure, and the state-law instrument provides the compulsion. 42 C.F.R. $\S \S 2.33,2.61$ (1994).

31. 42 C.F.R. $\$ 2.31$ (1994).

32. A sample notice is provided in $\S 2.32$ of the 1994 edition of the Code of Federal Regulations. This provision is extremely important because it extends the requirements of the federal confidentiality law to every person or organization that receives confidential information, thereby prohibiting that recipient from engaging in any redisclosure. See 42 C.F.R. $\S 2.32$ (1994). 
Of all the requirements for a disclosure pursuant to patient consent, perhaps the most critical is the mandated purpose statement. ${ }^{33}$ Treatment programs must designate the purpose of the disclosure before determining the scope of the communication, the recipient of the information, and the duration of the patient's consent. The logic here is that consent is a narrow exception to the general prohibition against sharing patient-identifying information, and an initial identification of purpose allows the patient and program to tailor consent to meet that purpose in the most conservative fashion possible. ${ }^{34}$

\section{B. Application of the Law to Head Start}

When applied to Head Start centers engaged in substance abuse "treatment" or "prevention," the federal confidentiality laws and regulations may become nearly unworkable. To understand why this is so, it is important to note that this entire scheme of legal regulation relies upon a fundamental distinction between "treatment programs" and "patients." Indeed, neither the federal statutes nor their implementing regulations contain any restrictions applicable to the sharing of information about a patient by other patients; the prohibition against disclosures of patient-identifying information applies only to a treatment program and its staff. ${ }^{35}$

In the context of Head Start, both the concept of "program" and of "patient" are highly problematic. With respect to the definition of "program," two distinct problems may be present. The first is that, by tradition and design, the boundaries between staff and parents within individual Head Start centers often are blurred. The second problem is that, even among Head Start staff who are not parents, it often becomes difficult to distinguish between personnel engaged in substance-abuse treatment and prevention functions from those engaged in more traditional Head Start functions. Both of these contested boundaries are important because they make it difficult to determine not only who is entitled to receive informa-

33. 42 C.F.R. $\$ 2.31(a)(4)$ (1994).

34. Thus, if a methadone maintenance program wishes to obtain a patient's consent in order to disclose information to that patient's dentist for the purpose of determining an appropriate anesthetic during dental surgery, it should limit the kinds of information disclosed, for example, methadone dosage levels, but not counseling notes; the duration of consent, for example, expiration upon completion of the surgery; and even the recipient, for example, the dentist, but not her office staff, in a fashion that is consistent with the underlying purpose.

35. In my work over the past few years providing legal assistance to substance abuse treatment programs, I have found that patients frequently do come into contact with one another at treatment programs, and do occasionally share information with outsiders to the detriment of others in treatment. 
tion pursuant to the regulations' internal communication exception, but also to determine who will be bound under the federal laws not to redisclose patient-identifying material.

Some examples may help to clarify these points. As part of the Target Cities demonstration project in Baltimore, a number of individual Head Start centers hired an "on-site coordinator," responsible for managing a range of substance-abuse-related services directed to identified families. ${ }^{36}$ Clearly, these functions fall within the parameters of the confidentiality regulations, thereby raising the legal obligations described earlier. In addition, the demonstration project proposal also called for a series of "consensus building workshops" to be held at each center that would include all staff. ${ }^{37}$ The long-term goal of these workshops was to provide training to all Head Start personnel in drug- and alcohol-abuse issues, on the theory that everyone from teachers to parent liaisons to clerical staff to kitchen workers might well become involved, if they were not already, in the provision of "treatment" and "prevention" services. ${ }^{38}$

Given this broad-based involvement of staff and parents in treatment and prevention services, questions arise as to the scope and coverage of the federal confidentiality regulations. Suppose, for example, that a parent, knowing that all Head Start staff have received training on substance-abuse issues, bypasses the on-site coordinator and instead approaches a teacher's aide to discuss her alcohol abuse. ${ }^{39}$ Regardless of whether the teacher's aide simply listens empathetically or provides "services" in the form of referral information, counseling, or the like, a question is raised as to whether she is within "the program" governed by the confidentiality laws and regulations. The answer to this question is crucial because it determines the circumstances under which the teacher's aide will be able to share this information with other people inside or outside of the Head Start center who might be able to provide

36. Baltimore Urban Services Agency, Collaboration, supra note 5, at app. B.

37. Baltimore Urban Services Agency, Building the Capacity, supra note 5, at 11 (attempting "to prioritize the substance abuse related needs of the program and to develop plans for addressing these needs").

38. Significantly, the project description makes clear that these efforts are also designed to address alcohol and drug abuse among Head Start personnel. Here again, the line between service provider and service recipient is not terribly clear. Id.

39. Such a scenario is neither unlikely nor uncommon. In working with Baltimore-area Head Start centers, my students and I discovered that parents not uncommonly seek out those workers with whom they have the most daily contact, and hence trust, in order to obtain support or assistance for extremely serious and sensitive family problems. See Barker et al., supra note 13, at 24-25 (discussing the legal ramifications of such a scenario). 
assistance. Desired contacts might include other teachers at the Head Start center who might know whether the classroom behavior and performance of the parent's child indicates a possible substance abuse problem within the family, ${ }^{40}$ or personnel at nearby treatment programs who might be in a position to work directly with the parent. The designation of the teacher's aide as either within or outside of "the program" would determine the steps the aide or another staff member would have to take, including obtaining the parent's written consent, in order to make such disclosures.

These kinds of interpretive problems arise in this context because Head Start centers, unlike more conventional social service settings, tend not to be rigidly organized into units or departments, and tend not to have unyielding role-specific job descriptions. Most Head Start staff members perform a much broader array of overlapping functions than is typical at other social service agencies. ${ }^{41}$ Thus, though it is clear that the federal confidentiality restrictions apply in some fashion to a Head Start center engaged in the kinds of activities envisioned by the Target Cities initiative, because the center "hold[s] itself out to the community as providing diagnosis, treatment, or referral for treatment for alcohol and/or drug abuse," as the regulations require, 42 it is considerably less clear whether these restrictions should apply only to certain designated personnel or to all staff members without regard to title or payroll status. ${ }^{43}$

40. For a good discussion of the kinds of observations that might lead a classroom teacher to conclude that a child has been exposed to substance abusing adults, see Collins \& ANDERSON, supra note 2, at 23-24.

41. See Barker et al., supra note 13.

42. The Legal Action Center of the Chty of New York, Inc., Confidentialtix: A Guide To tHE NEw Federal Regulations $73-74$ (1988).

43. Unlike the hypothetical conversation in text, a conversation between an alcoholic patient and a nurse's aide in a general hospital would not be sufficient to bring the federal confidentiality regulations into play, unless the nurse's aide were assigned to a specialized substance abuse treatment unit or otherwise had as her or his "primary function" the treatment of drug or alcohol abuse. 42 C.F.R. $\$ 2.11$ (1994), which sets out these rules relating to the definition of "the program" in a general medical care facility, is subject to two plausible interpretations. Under the first, the requirement of staff specialization can be understood to apply to any institution, such as a community mental health center or school, that performs substance abuse treatment or prevention functions. Under this interpretation, the lack of departmentalization or specialization within individual Head Start centers makes the question of the applicability of the confidentiality regulations especially difficult to resolve. The second interpretation, which eases Head Start's legal problem somewhat, is that the regulations' limitation to identified units is meant to apply only to general medical hospitals. If this interpretation were to prevail, it would be easier to argue that the confidentiality regulations apply to all Head Start personnel, because all staff members would be considered to be within "the program." There is some support for this second interpretation in the history of the revised 1987 regulations. Under the former regulations, no limitations based upon specialization or departmentalization had been present, and the confidentiality protections covered alcohol or drug abuse treatment records without regard to the nature of the entity that had delivered those services. See Legal Action Center of the City of New York, Inc., supra 
Equally difficult to manage within the context of the federal confidentiality laws and regulations is the tendency in many Head Start centers not to make rigid distinctions between parents and staff. As will be explained in more detail in Part II, this lack of differentiation is a product, in part, of longstanding legal requirements that parents be involved in Head Start under the Office of Economic Opportunity (OEO) principle of "maximum feasible participation." ${ }^{44}$ This directive has come to be understood not simply as a requirement that parents be included as "learners" but also that they be utilized as teachers, support staff, and "decision makers." 45 As will be discussed in Part III, the inclusion of parents in all facets of Head Start's operations can be attributed to the values, interactive styles, and experiences of those who have been associated with the program from its inception: principally women, and especially women of color. ${ }^{46}$ Together, these influences have generated an organizational model that tends to emphasize relationshipbuilding more than independence, cooperation more than competition, and general involvement more than hierarchical role differentiation. ${ }^{47}$

note 42, at 73. According to the transmittal notice issued by the Alcohol, Drug Abuse, and Mental Health Administration of HHS that accompanied the new regulations, the additional requirements were meant to ease the "administrative burden" flowing from application of the confidentiality prohibitions to hospital emergency rooms and surgical wards. Significantly, no mention was made of departmentalization in other institutional settings. Id.

44. Jeanette Valentine \& Evan Stark, The Social Context of Parent Involvement in Head Start, in Protect Head Start: A Legacy of the War on Poverty 291-93 (Edward Zigler \& Jeanette Valentine eds., 1979).

45. Id. at 295-98; see also Midco Educ. Assocs., Perspectives on Parent Partictipation In Project Head Start. An Analysis and Critique I-50 to I-80 (1972).

46. See generally Lucie E. White, Client Involvement in the Governance of Head Start (1990) (unpublished narrative of a grant application to the Law and Social Science Program of the National Science Foundation, grant \#SES9022787, on file with author) [hereinafter White, Client Involvement]; see also White, supra note 12, at 2001-02.

47. For a good general discussion of "organizational types" among grassroots community organizations, see Lucie E. White, Collaborative Lawyering in the Field? On Mapping the Paths from Rhetoric to Practice, 1 ClinICAL L. REv. 157, 164-66 (1994) [hereinafter White, Collaborative Lawyering]. Interestingly, Professor White treats Head Start as a "state-sponsored initiative" that is "both structured and funded by the state," and she describes some other organizations as organizationally less rigid. Her account of one example of this latter type of group, an organization for drug-involved women, is in fact a particularly apt description of the findings that my students and I made with respect to our Head Start clients:

[T] hese groups ... also tend to be less patemalistic and organizationally rigid than charitable initiatives. These initiatives wrestle with the traditional role definitions of "client" and "helping professional" because their members have experienced the distance and insensitivity of professionals, but at the same time recognize their own need for help.

Id. at 165 . The capacity of many Head Start centers to retain a relatively nonbureaucratic organizational style despite being sponsored and funded by the government is something of an irony. I attempt to offer some partial explanations for this below. See infra text accompanying notes 144-57. 
One fairly simple method for distinguishing staff from nonstaff might be to identify those who are on Head Start's payroll as staff. Unfortunately, such an approach would not comport with the practice of many centers to rely heavily upon unpaid volunteers and to grant considerable policy-making power to parents. ${ }^{48}$ In addition, for years Head Start has employed a large number of parents and has utilized a "career ladder" approach in which employees are encouraged to progress from volunteer to paid staff. 49 Finally, in the context of projects like the one undertaken in Baltimore, responding to the drug and alcohol problems of staff members has been nearly as high a priority as the effort to assist Head Start parents with their substance abuse problems. ${ }^{50}$

In light of these organizational characteristics, it would not be unusual for an alcoholic parent to seek referral information or other help from a teacher's aide who is herself a Head Start parent. As just noted, it is common for mothers, and sometimes fathers, of enrolled children to be present in Head Start classrooms as volunteers. ${ }^{51}$ Under this version of the hypothetical, the confidentiality rules might apply, given that the federal regulations make no mention of any requirement that program staff be on the payroll.52 If the requirements of federal confidentiality law bound the teacher's aide, however, she might be unable to seek assistance from others without first obtaining written consent, in which case the regulations would transform an informal conversation between the two Head Start parents into a formal therapeutic relationship between a treatment provider and her client, with all of the attendant distancing and potential alienation that such formality implies. ${ }^{53}$

This example illustrates that any effort to map the confidentiality rules onto the nonhierarchical milieu found within many Head Start centers will not be a simple matter. The federal laws' fundamental differentiation between service providers and service recipients was designed to encourage individuals designated as "patients"

48. See Midco Educ. Assocs., supra note 45; ANN O'KeEFe, What Head Start Means to Familes 9-12 (1979); Valentine \& Stark, supra note 44.

49. See Penelope K. Trickett, Career Development in Head Start, in Project Head START, supra note 44, at 315; see also O'KEEFE, supra note 48, at 9.

50. See Baltimore Urban Services Agency, Building the Capacity, supra note 5.

51. Alternatively, the teacher's aide might be the parent of a former Head Start student who has now moved up the "career ladder" to occupy a paid paraprofessional position within the center.

52. Indeed, the parent seeking help for her alcoholism might herself be a staff member of the Head Start center.

53. See William Simon, Legality, Bureaucracy, and Class in the Welfare System, 92 YALE L.J. 1198, 1233-35 (1983); see also infra text accompanying notes 185-88. 
to seek treatment from entities designated as "programs" by ensuring that the status and identity of the former would be safeguarded by the latter. When applied to Head Start, this regulatory scheme is often inappropriate.

The world of Head Start is comprised of people, designated as "parents," who are already engaged, sometimes deeply, in the collective enterprises that make up Head Start. Rather than encourage participation in substance abuse treatment through confidentiality, Head Start centers may best be able to intervene in the lives of families suffering from substance abuse by building upon the trust already developed through ongoing interactions and stable relationships at the center. How to balance the beneficial aspects of individual privacy against the clinical potential of relationships and collective engagement is no easy matter, however. ${ }^{54}$ What is important for the purpose of this article is to recognize that the federal confidentiality laws and regulations have answered this question by uniformly insisting on protecting the privacy of individual rights holders. Part III of this article explores the possibility of gẹnerating a more relationship-based answer.

The difficulties involved in defining a "patient" in the Head Start context are as great as those already encountered with respect to the definition of a "program." Here, questions relating to the meaning of statutory and regulatory language are not the primary obstacle. Instead, the task is how to apply relatively clear prescriptions to a setting in which obvious interpretations may not create the most effective results.

As previously explained, the federal confidentiality regulations define a "patient" as an "individual" who has applied for or received diagnosis, counseling, or referral services from a drug or alcohol abuse treatment program. ${ }^{55}$ Given this language, it seems reasonable to conclude that the drafters intended to protect the privacy interests of individuals suffering from substance abuse. A fundamental tenet of Head Start, however, is that services should be directed not to individuals but to "families." 56

54. This question has long vexed "therapeutic communities," which are residential drug and alcohol treatment programs in which clients spend as long as $\mathbf{1 8}$ months in treatment. Typically, toward the end of their stay, usually during their last six months, clients begin to perform staff functions. The clear distinctions drawn between patients and staff in the federal confidentiality regulations have never fit well in this clinical setting. See generally William B. O'Brien \& D. Vincent Biase, Therapeutic Community (TC): A Coming of Age, in SuBStANCE Abuse: A Comprehenstve Textbook 446 (Joyce H. Lowinson et al. eds., 2d ed. 1992).

55. See supra text accompanying note 22 .

56. See O'KeEFE, supra note 48 , at 3. 
As early as 1965, initial Head Start planners began developing a philosophy that viewed children "within the context of the family and community."57 By 1975, the Performance Standards for Head Start Programs had made clear that "[ $t]$ he child's entire family, as well as the community must be involved."58 These principles have long guided the development of policy in local Head Start agencies, and have led to important programmatic innovations like the Child and Family Resource Program (CFRP), which was launched in eleven cities in the early 1970's as a "family-focused demonstration project."59 Indeed, building upon the family-centered approach characteristic of Head Start's enterprise, and recognizing the complex family dynamics associated with drug addiction and alcoholism, ${ }^{60}$ the Baltimore Target Cities project and others like it have identified the need to direct substance-abuse-related services to the whole family unit as a central feature of their efforts. ${ }^{61}$

Once again, the Head Start approach is at odds with the structure of the confidentiality law. A particularly good illustration of the federal regulations' individualistic perspective involves the rules governing minors who have sought or received treatment. In some states, minors may enroll in drug or alcohol treatment without the consent of their parents. ${ }^{62}$ In these states, the federal regulations provide that any communication of patient-identifying information to the minor's parent or parents will constitute a prohibited disclosure unless it can be brought within one of the recognized exceptions, principally consent. ${ }^{63}$ In states that still require parental notification or approval for the treatment of a minor, the confidentiality implications become somewhat more complicated. In these states, the federal regulations prohibit the treatment program from

57. Id. (footnote omitted). The term "family" was not defined in these early documents. For present purposes, an appropriate definition might regard a family as "any child-rearing structure."

58. Id. at 4.

59. Id. at 34. Significantly, the "unit of enrollment" in CFRP was the family, rather than the individual child, and the goal was to promote the "healthy development of the young children in the family from the prenatal stage through the third grade." Id. at 35 . In many ways, the current Target Cities initiative can be understood as a successor to this early program.

60. See generally Eileen M. Corrigan, Alcoholic Women In Treatment 86-130 (1980); George Winokur \& Paula Clayton, Family History Studies: Comparison of Male and Female Alcoholics, 29 Q.J. STUD. Alcohol 885 (1968).

61. This central feature is evidenced by the plan to hire on-site coordinators to manage the family's substance abuse problems in a "holistic" fashion. See Baltimore Urban Services Agency, Building the Capacity, supra note 5, at 2-3.

62. See, e.g., MD. CODE ANN., HEALth-GeN., § 20-102(c)(1) (1990).

63. 42 C.F.R. \& 2.14(b) (1994). 
communicating with the parents in order to obtain their approval unless the minor, whose involvement in treatment may be as minimal as an initial phone inquiry, first consents to the "disclosure" of her or his "patient" status. ${ }^{64}$

This highly individualistic definition of "the patient" takes on a special meaning when it is applied to the regulations' internal program communication exception to the general prohibition against disclosures. The regulations allow for the communication of information "between or among personnel having a need for the information in connection with their duties that arise out of the provision of diagnosis, treatment, or referral for treatment" of the patient.65 In most therapeutic settings, this provision is relied upon with some regularity, and it is simple to apply. ${ }^{66}$ In the Head Start setting, on the other hand, this provision excludes a whole range of communications essential to its holistic approach to treating families.

For example, if the internal communications exception is limited to information necessary to help treat a parent's abuse of drugs or alcohol, then the regulations force a teacher who wishes to share information about the parent's substance abuse in order to facilitate the delivery of services to that parent's child to obtain separate consent from the parent. While this requirement is not on its face unreasonable, it could severely inhibit ongoing collaborative efforts between teacher and parent, particularly if the need for individual, written consent were to arise several times each day.

An alternative construction of the term "patient" that reflected the Head Start philosophy might include not only the parent, but her or his children, or even the entire family in some cases. This construction would be at odds with the plain meaning of the regulatory language and basic assumptions implicit in the confidentiality laws. Nevertheless, the potentially close connections between a parent's abuse of drugs or alcohol and her or his child's behavior or progress in the classroom, and the equally close links between the development of the child and her or his parent's substance abuse, could be exploited for the benefit of the whole family unit, if an expanded definition of the term "patient" could be employed.

To be sure, this sort of expansion of the term "patient," with its attendant diminution of individual privacy within a Head Start

64. 42 C.F.R. $\$ 2.14$ (c) (1994).

65. 42 C.F.R. § 2.12(c)(3) (1994).

66. See Legal Action Center of the City of NEW York, Inc., supra note 42, at 20. 
center, carries real dangers of abuse. Relaxing the prohibition on disclosing information about a parent's drug or alcohol problems might disincline some individuals from confiding in counselors or otherwise seeking help. ${ }^{67}$ This relationship between legal rights and individual decisionmaking is at the heart of the federal confidentiality laws and regulations. ${ }^{68}$ The system of services being developed within Head Start, however, presumes a very different approach founded upon trust and connection. Determining whether this alternative approach to structuring relationships between providers and recipients of services is better or worse than the one promulgated in the federal regulations is difficult. What is not difficult to discern is the gap between the perspective endorsed by the law and the behavior embodied in the actual operation of Head Start programs throughout the country.

\section{Head Start: The Development of Alternative Political Cultures}

Since its inception in the mid-1960s, Head Start centers throughout the United States have provided education, health, and other social services to over 11 million children and their families. ${ }^{69}$ Currently, more than 700,000 children between the ages of three and five are enrolled in Head Start. ${ }^{70}$ Recent studies report that over 90 percent of all Head Start families live below the poverty line, and more than half are headed by a single parent. ${ }^{71}$ Roughly threequarters of all participants in Head Start are people of color. ${ }^{72}$

Significantly, in the current age of skepticism about government initiatives, Head Start has generally received praise and support: In the past several years, leading Democrats in the House and Senate have sponsored legislation to expand greatly federal funding for Head Start, in order to insure a place for every income-eligible child between the ages of three and five. ${ }^{73}$ A number of Republi-

67. Cf. White, Collaborative Lawyering, supra note 47, at 167 (describing the negative reactions of poor women to intrusive community group practices that fail to respect clients' privacy or autonomy).

68. See Legal Action Center of the Ctry of New York, Inc., supra note 42, at 2.

69. Report of the Silver Ribbon Panel, National Head Start association, Head Start. The Nation's Pride, A Nation's Challenge 1 (1990) [hereinafter Report of the SILVer RibBon PANel].

70. Barbara Vobejda, Head Start Expansion is Urged, WASH. Post, Jan. 13, 1994, at 4.

71. REPORT OF THE Silver RibBon PANEI, supra note 69, at 1.

72. See id. at 2.

73. This would amount to some 2.5 million children. On May 18, 1994, President Clinton signed into law a bill authorizing a significant expansion of the Head Start program. The House vote in favor of the bill was 393 to 20, while the Senate vote was 98 to 2. Vice Presi- 
cans, including former President Bush, have also expressed strong support, ${ }^{74}$ although the current Republican leadership is seeking reductions in Head Start's funding. Business leaders have joined the chorus of supporters, ${ }^{75}$ and new strategies have been proposed to strengthen ties between Head Start and the business community. ${ }^{76}$ Recent public opinion polling has indicated that a majority of Americans believe Head Start should be expanded.77

The story of Head Start's genesis and development over the years has been told and retold by numerous writers. ${ }^{78}$ Some accounts depict a program design based upon the theoretical work of child development experts, physicians, and educators who saw Head Start as an opportunity to interrupt a "cycle of poverty" by helping poor children overcome "cultural deprivation."79 Other histories stress the importance of Head Start's roots in the community action movement of the late $1950 \mathrm{~s}$ and $60 \mathrm{~s} .{ }^{80}$ These accounts argue for the central importance of the parental involvement component of the program, and suggest that, from the beginning, Head

dent Gore called final passage of the bill a "love fest." The legislation included a $\$ 595$ million increase in funding, and plans to expand the program to children under the age of three. It also called for the development of some full-day, year-round classes. See Helen Dewar \& Barbara Vobejda, Clinton Signs Head Start Expansion, WASH. Post, May 19, 1994, at A1, A6; see also Ronald Henkoff, Now Everyone Loves Head Start, 121 ForTune MAG., Spring, 1990, at 35. In July of 1995, however, a House Appropriations subcommittee voted to cut a number of education programs for the poor. The plan would reduce Head Start's budget somewhat. See Tilting Against the Poor, N.Y. TIMES, July 13, 1995, at A22.

It is worth noting that the Head Start program has recently come in for criticism as well. Several reviews by the Inspector General have identified problems with physical facilities and lax paperwork, and other studies have noted that low pay scales have made it difficult to attract and retain effective teachers. In response to these reports, Health and Human Services Secretary Donna E. Shalala appointed a 48-member Advisory Committee on Head Start Quality and Expansion. In January of 1994, the Advisory Panel issued a report recommending enhanced teacher training, upgraded salaries, and greater professionalism in the management of the program. See Vobejda, supra note 70. Although many of these recommendations are sound, the report does raise the concern that an increased "professionalization" of Head Start will undermine the distinct local culture that has, in part, made this program so effective. See infra Part III.

74. George Bush, The State of the Union, quoted in Wask. Post, Feb. 1, 1990, at A8. Nevertheless, the most recent Republican budget proposals call for cutting Head Start by $\$ 210$ million below 1995 funding levels. This would result in a reduction of 180,000 children by the year 2002. Rene Sanchez \& John F. Harris, Direction, Not Dollars, Drives Debate over Education, WASH. Post, June 22, 1995, at A29.

75. Henkoff, supra note 73.

76. Report of the Silver Ribion PANel, supra note 69, at 46.

77. See id. at 4.

78. See generally Protect Head Start, supra note 44.

79. Most of those who served on an initial planning committee convened in January of 1965 by OEO Director Sargent Shriver meet this description. Edward Zigler \& Jeanette Valentine, Head Start, A Retrospective View: The Founders, in Project Head Start, supra note 44 , at 72 .

80. See Midco Educ. Assocs., supra note 45, at I-12 to I-18. 
Start had the potential to help organize and empower poor communities. ${ }^{81}$ Still other histories tell a story that focuses on domestic political controversies surrounding the Johnson Administration's war on poverty, the civil rights movement, and simple.political expediency. ${ }^{82}$ More recently, scholarly work has examined the local culture within many Head Start centers as an example of how sustained interactions between groups of subordinated people and a welfare bureaucracy can lead to creative, new social structures. ${ }^{83}$

Each of these accounts captures at least a part of the story. Perhaps what is most important about Head Start, its tradition of parental involvement, and its current status as a social service enterprise that "works," 84 however, is how these histories have operated together over time. It is worth constructing a short composite account of these histories in order to make possible the analysis Part III of this article sets forth.

From the beginning there has been a strain of thought surrounding the Head Start project that can best be described within the terms of conventional liberalism. ${ }^{85}$ This perspective, which views poverty and racism as unfortunate abnormalities within the larger culture, urges the application of special remedial resources delivered through a welfare bureaucracy as the best means for eradicating - or in the language of the 1960s, "curing" - these problems. ${ }^{86}$ At the same time, and throughout its existence, an alternative perspective has also energized the activities of some Head Start participants. According to this perspective, the range of problems associated with poverty are not solely the result of inadequate resources, but are due in large measure to the diminished political power of subordinated communities. ${ }^{87}$ Not surprisingly, advocates of this approach, though concerned about the delivery of services to poor clients, were far more interested in organizing com-

81. These accounts build upon the early influence of community organizers, including Saul Alinsky, and community organizations such as Mobilization For Youth. See infra notes 102-11 and accompanying text.

82. See Edward Zigler \& Karen Anderson, An Idea Whose Time Had Come: The Intellectual and Political Climate, in Project HeAD StART, supra note 44, at 12-16.

83. White, Client Involvement, supra note 46; White, Collaborative Lawyering, supra note 47.

84. See Everybody Likes Head Start, NewsweEk, Feb. 20, 1989, at 49.

85. For a helpful discussion of the basic elements of liberalism, see Howard Lesnick, The Wellsprings of Legal Responses to Inequality: A Perspective On Perspectives, 1991 Duke L.J. 413, 426-31. See also infra section III.B.

86. Lesnick, supra note 85; see also Sargent Shriver, The Origins of Head Start, in ProJECT HEAd START, supra note 44, at 49.

87. See, e.g., Richard A. Cloward \& Lloyd E. Ohlin, Delinquency and Opportu. NITY: A Theory OF Delinguent Gangs (1960). 
munity groups and working toward their empowerment and political self-sufficiency.8 8 This perspective - more difficult to characterize politically - received little official sanction in the original descriptions of the project. ${ }^{89}$ Nevertheless, it held sway with some planners within OEO's Community Action Program (CAP), and may have been responsible for the statutory injunction to seek the "maximum feasible participation" of community members in OEO programs such as legal aid, VISTA, and the like..$^{90}$

The history of Head Start, then, is a history of struggle between a then-prevailing liberal perspective and a more diffuse and potentially more radical perspective, both at the policymaking level and in the field. ${ }^{91}$ While both perspectives have been present within the program for more than twenty-five years, there has been a gradual - though uneven - strengthening of the latter approach, at least with regard to issues surrounding parent involvement in Head Start.

In some respects, the most telling feature of this history has been the persistent tendency of government policy and legal regulation to lag one step behind the day-to-day reality of family and community involvement in Head Start that appears to have arisen "spontaneously." 92 Whether this pattern has operated to legitimate and rationalize the successes in self-governance and community organization Head Start families accomplished, as some have suggested, or to restrain the energy of that grassroots movement, as

88. Save for its placement within OEO's Community Action Program (CAP), little or no mention was made of parental control or community organizing within the original documents which began Project Head Start, and even the decision to work within CAP was probably the result primarily of the Johnson Administration's desire to minimize political criticism directed at CAP by including a program for children, always an especially favored group within the political culture. See Mrdco Educ. Assocs., supra note 45, at I-54 to I-55. Despite this initial ascendancy of the liberal perspective among Head Start's planners, a grassroots political activism on the part of Head Start parents has also been present from the beginning. See Valentine \& Stark, supra note 44, at 304-07.

89. See, e.g., Lyndon B. Johnson, Remarks On Project Head Start, (May 18, 1965), in Project Head Start, supra note 44, at 67-69.

90. There has been considerable controversy regarding the origins of this phrase, as well as the intention of its authors. Although there is virtually no legislative history available to assist in answering these questions, see Mmco EDuc. Assocs., supra note 45, at I-40 to I-45, some writers have argued that it was intended to protect African Americans in the southem states, see, e.g., Daniel P. Moyniman, Maximum Feasible Misunderstanding 86 (1969), while others have claimed that it was meant to make welfare programs more accountable to those intended to be served, see, e.g., Sanford J. Kravitz, Community Action Program - Past, Present, and Its Future, in ON Fighting Poverty: Perspectives From Experience 68 (James L. Sundquist ed., 1969).

91. The terms "liberal" and "radical" are being used in a qualified manner, as an attempt to capture the relative perspectives at contest in this history. These labels are meant to carry the meanings ascribed to them in Lesnick, supra note 85.

92. Valentine \& Stark, supra note 44 , at 306. 
others have claimed, ${ }^{93}$ is an open question. What is clear, however, is that this unconventional model has grown and persisted despite a political climate that otherwise has been explicitly hostile to such undertakings.

The competition between the liberal and the radical perspectives has been most visible with respect to the question of parental role within Head Start.94 One model of parental involvement has focused on the task of helping Head Start mothers, and, occasionally, fathers, acquire better parenting skills. Several writers have labelled this perspective the "cultural-deprivation model."95 It has been described as follows:

[T]he poor themselves perpetuate poverty: They share traits, habits, values, and aspirations that they transmit to their children in the same way other cultural patterns are transmitted. In this way, a "cycle of poverty" is established. At the same time the poor resist, fail to develop, or are denied the experiences from which alone come the traits needed for "success." The problem, then, is a dual one: to replace the culture of poverty with middle-class habits and to introduce those experiences that the poor lack, experiences that are prerequisites for success. ${ }^{96}$

A majority of Head Start's initial planning committee held some version of this "cultural-deprivation" perspective. Many of these experts had served on, or were influenced by, President Kennedy's Panel on Mental Retardation. This earlier panel's study of mental retardation indicated that "slow learn[ers]" in "urban and rural slums" lacked "motivation toward achievement," and suffered from "disorganized" families devoid of "middle-class values." 97 In so finding, the panel explicitly rejected the then-current belief that "personality traits associated with poverty were inherited." 98 Instead, since they credited the findings of researchers that the "intellect is, to a large extent, a product of experience, not inheritance,"99 their recommendations for breaking the "cycle of poverty" cen-

93. See id. at 308-09.

94. See id. at 302.

95. See generally Chardes Valentine, Culture and Poverty: Critique and CounTERPROPOSALS (1968).

96. Valentine \& Stark, supra note 44, at 299; see also Midco Educ. Assocs., supra note 45 , at I-2 to I-12 (collecting authorities).

97. Valentine \& Stark, supra note 44, at 300-01; see also Mrbco EDuc. Assocs., supra note 45, at I-7 to I-10; Shriver, supra note 86, at 49-54.

98. Robert E. Cooke, Introduction to ProJect HeAd Start, supra note 44, at xxiii.

99. Id. 
tered upon the development of a network of preschool centers to be "built in connection with every low-cost housing project."100

As reinterpreted by the early Head Start planners, these recommendations of the Mental Retardation Panel led to a belief that a relatively short-term, early education program for poor children could provide something like an "inoculation" against the debilitating influences found in their family and community environments. ${ }^{101}$ Correlatively, if the parents could also receive training in more effective parenting skills, their children's inoculation might persist. Thus, as originally conceived, the cultural-deficit model clearly envisioned the involvement of parents as "learners" and as recipients of services, but not as equal participants in a collaborative endeavor.

At roughly the same time that the Mental Retardation Panel developed the cultural-deficit model, policy analysts affiliated with the Ford Foundation and the President's Committee on Juvenile Delinquency were developing a second, somewhat more radical model. ${ }^{102}$ This alternative model stemmed from a critique of existing welfare programs as "unresponsive" and "irrelevant" to the communities they were intended to serve. ${ }^{103}$ In particular, these analysts argued that social service workers operating in poor communities had failed to understand that most of the problems confronting their clients were interrelated and structural. Because clients had little or no participation in the design or implementation of programs, the professionals involved often had an unrealistic understanding of the problems they were seeking to ameliorate. As a consequence, the services they offered were fragmented and often inappropriate. ${ }^{104}$

In an effort to respond to these criticisms of existing social service agencies, the President's Delinquency Committee sponsored three demonstration projects, the most famous of which was Mobilization for Youth on the lower East Side of New York. ${ }^{105}$ The design of these demonstration projects was based upon the work of Richard Cloward and Lloyd Ohlin, who had argued that juvenile delinquency among the poor was not primarily the result of individ-

100. Valentine \& Stark, supra note 44 , at 300 (quoting TASK FORCE ON PREvention, 1962 Presidential Report ON MENTAL Retardation).

101. Johnson, supra note 89 , at 67-68.

102. See Mmco Educ. Assocs., supra note 45, at I-12 to I-14.

103. MoYnihan, supra note 90 , at 69 (quoting Sanford Kravitz).

104. See Mrdco Educ. Assocs., supra note 45, at I-12 to I-14.

105. The other two were located in Harlem, New York and New Haven, Connecticut. See Valentine \& Stark, supra note 44 , at 301. 
ual character flaws, a culture of poverty, or any other deficits specific to the ghetto or its inhabitants. Instead, they argued that delinquency among the poor was a predictable consequence of a larger social and political order in which opportunity was systematically denied to poor communities of color. ${ }^{106}$

Because the emphasis within this alternative model was on the structural impediments to opportunity confronting young people in poor communities, the prescriptions offered by the Committee on Juvenile Delinquency and the policy papers coming out of Mobilization for Youth ${ }^{107}$ rejected individually targeted social services of the kind urged by liberals. Instead, they urged community-based strategies designed to foster local leadership and community competence. ${ }^{108}$ A number of OEO planners outside of the Head Start program ${ }^{109}$ espoused this "institutional change model," as some writers have called it,, 10 and this model thus found its way into OEO's community action programming, where it immediately drew criticism. ${ }^{111}$

Among those involved in the development of the first Head Start demonstration program, the "institutional change" or "empowerment" model, and its implications for parental involvement, held little sway. ${ }^{112}$ Had this potentially more radical perspective

106. See Cloward \& OHLIN, supra note 87. Cloward and Ohlin's work built upon the theory of anomie as developed by Emile Durkheim and Robert Merton. See Emire DurkHEIM, The Division of LABOR IN SocieTy (George Simpson trans., Free Press 1964) (1893); Robert Merton, Social Theory and Soctal Structure 121-94 (rev. ed. 1957).

107. See, e.g., Richard A. Cloward \& Irwin Epstein, Private Social Welfare's Disengagement from the Poor: The Case of Family Adjustment Agencies, in COMmUNITY ACTION Against Poverty: ReAdings FROM the MobILIZATION EXPERIENCE 40 (George A. Brager \& Francis P. Purcell eds., 1967).

108. The idea of community competence was developed by Nelson Foote and Leonard Cottrell, who described it as follows:

Competence denotes capabilities to meet and deal with a changing world, to formulate ends and implement them. The incessant problem of equipping human beings to handle their affairs and to progress towards the discovery of new values and new means is not solved by authoritarian indoctrination of static attributes and beliefs.

NELSON N. FoOTE \& LEONARD S. COTTRELI, JR., IDENTITY AND INTERPERSONAL COMPETENCE 49 (1955).

109. See MoYNIHAN, supra note 90.

110. Valentine \& Stark, supra note 44, at 301.

111. See Shriver, supra note 86 , at 59 . To be sure, earlier demonstration projects like Mobilization for Youth and Haryou-Act, which had "openly supported street action and employed radicals," expressed a more unalloyed version of the radical perspective. OEO's Community Action Program, by contrast, was a much tamer amalgam of radical and liberal elements that sought to deliver services as well as stimulate political change. Valentine \& Stark, supra note 44 , at 302 .

112. Minco Educ. Assocs., supra note 45, at I-53. A few members of Head Start's initial planning committee who did object to this limited conception of parental role took their concerns to Sargent Shriver. They did not prevail. See id. at I-52 to I-53; see also Valentine \& Stark, supra note 44 , at 303. 
taken hold among the early Head Start planners, there might have been some recognition of the need to involve parents not simply as "learners" or helpers, but also as decisionmakers. Instead, operating almost entirely within the cultural-deficit model, the planners conceived of a program in which parents would receive services along with their children but would play no other roles. ${ }^{113}$

As a number of writers have observed, ${ }^{114}$ some features of the original Head Start offering were the result of the hasty manner in which it began. The program was originally conceived as a summer project for up to 25,000 children. ${ }^{115}$ Within a few months, the plan had become so popular politically that the first summer demonstration involved half a million children. ${ }^{116}$ In order to provide services on this scale, the federal program made extensive use of public school facilities that would otherwise be idle during the summer months, as well as public school teachers.117 Similarly, because "[t]he major concern was whether or not a high-quality program could be quickly and cheaply produced on a mass scale," discussion of parent roles in the program focused upon their use as volunteer aides and helping hands. ${ }^{118}$ When coupled with the ascendancy of the cultural-deficit model within the planning group, it is not surprising that the group gave little attention to the possibility that parents might play a significant role in the design, development, and governance of their local programs.

This view of parents as "adjuncts to the program,"119 is clearly reflected in the first official guidelines for Project Head Start.120

113. See Mroco EDUC. Assocs., supra note 45, at I-52. This last statement should be clarified somewhat. The "Cooke Memo," which was the first official statement of Head Start policy, did set out "multiple roles" for parents. Thus, they were to function as teachers' aides, volunteers, and observers. Nevertheless, it was plain that early Head Start policymakers did not recognize parents as significant participants in the development of local policies, nor were parents targeted for community organizing. It was this rather limited conception that Saul Alinksy, a leading proponent of the empowerment model, termed "poverty pornography." Id. at I-25, I-51; Shriver, supra note 86, at 60; see also Saul D. Alinsky, The War on Poverty - Political Pornography, in POVERTY: POWER AND POLITICs 171 (Chaim Isaac Waxman ed., 1968).

114. See, e.g., Midco Educ. Assocs., supra note 45, at I-50 (citing Mary Ann Beattie, The Story of Head Start (unpublished manuscript)).

115. See Shriver, supra note 86 , at 55.

116. See Mrnco EDuc. Assocs., supra note 45, at I-58. The start of the first Head Start demonstration project was marked by a massive public relations effort, which included a very visible role by First Lady Lady Bird Johnson. See id.

117. See Shriver, supra note 86, at 55.

118. Id. at I-52.

119. Id. at I-64.

120. The first Head Start guidelines were contained in a memo from Dr. Robert Cooke, chair of the Planning Committee, to Sargent Shriver, the head of OEO. This memo, which 
These guidelines, which stood as the only authoritative statement of program policy until OEO issued the first Head Start Policy Manual in 1967, ${ }^{121}$ referred to parents as helpers, learners, and sources of information, but not as primary decisionmakers. ${ }^{122}$

In 1966, in response both to local demands for more parent and community participation ${ }^{123}$ and to advocacy on the part of some CAP staff members, ${ }^{124}$ OEO issued proposed guidelines that directed Head Start centers to establish "Policy Advisory Committees," to be made up of "consumers," staff, and representatives of the community. In addition, the proposal called for parents to have a veto power over basic administrative decisions such as budgeting and staff hiring. ${ }^{125}$ In a number of cities, local school boards opposed the proposed guidelines because they feared that the Advisory Committees were a first step toward greater parental control over education policy more generally. As a consequence, OEO backed away from its initial position and, in 1967, issued final guidelines that retained the Advisory Committees as consultative bodies only denying them any veto power. ${ }^{126}$

In the long run, a more important and contradictory feature of the 1967 policy manual was that it placed Head Start squarely within OEO's Community Action Program, and required a Head Start grantee in a community without a CAP to proceed "as if it were a community action agency." 127 By virtue of this reiteration of Head Start's place within CAP, OEO solidified the statutory requirement that programs seek the "maximum feasible participation" of parents. ${ }^{128}$ For the first time, an official Head Start document also spoke about parents as decisionmakers. ${ }^{129}$

These decisions were followed in 1969 by the designation of a paid staff position within Head Start, the parent coordinator, whose

was entitled "Recommendations for a Head Start Program by a Panel of Experts," is quoted extensively in Midco Educ. Assocs., supra note 45, at I-62 to I-64.

121. See id. (discussing the U.S. Department of Health, Education and Welfare, Office of Economic Opportunity, Manual 6108-1, Head Start Development Program: A Manual of Policies and Instructions (1967)).

122. See id. at I-74 to I-75; see also Valentine \& Stark, supra note 44, at 303.

123. See Valentine \& Stark, supra note 44, at 304.

124. See Minco Educ. Assocs., supra note 45, at I-65.

125. Valentine \& Stark, supra note 44, at 304.

126. See id.

127. Midco Educ. Assocs., supra note 45, at I-69 to I-70.

128. The efforts of OEO field inspectors, who "during the early days of OEO took as one of their main charges the implementation of the 'maximum feasible participation' " requirement, were probably a significant influence in this regard. Id. at I-67.

129. Id. at I-74. 
job it was to ensure the full participation of parents. Now, all the pieces were in place to ignite a grassroots organizing effort that went far beyond the original liberal conception of parental role. As one history of Head Start tells the story:

[A]s community pressure on public schools intensified, numerous "battles" ensued within local Head Start programs. PACs [Policy Advisory Committees] attempted to control the parent coordinator; staff and parents fought over program content; parents criticized local school officials; and, finally, local Head Start - often allied with local CAP - battled regional CAP, often allied with local school officials. New community organizations were created to give parents and neighborhood residents a greater role in school policy. The Pyramid Councils in Minneapolis, the Community Councils in New Haven, and the Neighborhood School Boards in New York had their counterpart in dozens of other cities where a militant parents' movement had developed. Simultaneously, threats to cut Head Start funds were used to confine parent involvement within safe bounds. According to the cultural-deficit model, parent "apathy" was a major obstacle to educating the poor. But now, as [Head Start staffer] Bessie Draper describes it, the staff "simply had no idea how to handle the numbers of poor persons who wanted to become involved in the program."130

In 1970, in reaction to these local developments, federal Head Start officials issued new guidelines. For the first time, official policy spelled out in detail the role of parents as decisionmakers in Head Start, and granted them veto power over staff hiring and firing decisions. ${ }^{131}$ Although some writers have argued that the drafters of the 1970 revisions intended to limit any further expansion of the grassroots politics that had taken place in some localities, and were merely "formali[zing] specific and restricted parental decisionmaking power ... [that] fell far short of the 'self-determination' which parents in the largest cities had demanded,"132 others have pointed out that the changes showed "a steady progression towards increased parental influence." 133 Not only were parents given a veto power, but also the committees on which they served were no longer intended to operate in an advisory capacity: now, they were policymaking bodies. ${ }^{134}$

130. Valentine \& Stark, supra note 44 , at 305.

131. See id. at 305-07.

132. Id. at 307.

133. Midco Educ. Assocs., supra note 45, at I-78.

134. See id. In addition, the introduction to the 1970 guidelines contained language reflecting a position more radical than the simple cultural-deficit perspective that had predominated five years earlier. The introduction explained the importance of parent participation in the following terms:

Successful parental involvement enters into every part of Head Start, influences other anti-poverty programs, helps bring about changes in institutions in the community, and 
After 1970, funding cutbacks and general hostility from the Nixon administration led to retrenchment within many OEO programs. ${ }^{135}$ Of all the original OEO initiatives, Head Start was the most successful at retaining some of the participatory characteristics inherent in the notion of community action. Subsequent guidelines for Head Start continued to stress the role of parents as decisionmakers as well as learners, ${ }^{136}$ and although the program has long since ceased to be an engine for significant political transformation within the larger community, ${ }^{137}$ many Head Start centers have managed to perpetuate an internal ethic of collaboration and engagement across the role designations that divide clients from professionals in other social service agencies. ${ }^{138}$

For example, a 1978 study by Associate Control, Research, and Analysis, Inc. (ACRA) found that 89 percent of those serving on Head Start's policymaking councils were parents of current or former Head Start children. ${ }^{139}$ Moreover, the study indicated that 32 percent of Head Start's staff were parents of Head Start children, and that parent volunteering was extensive. ${ }^{140}$ Other researchers have found that "the number of [Head Start] parents who have gone on to become CAP directors, Head Start directors, consultants, teachers, officials in local and state governments, family day care providers, and business people is 'overwhelming' and 'incalculable." "141

These data - both anecdotal and otherwise ${ }^{142}$ - indicate that, despite the failure of community activists to turn Head Start into a catalyst for broad social change, the program has managed to create and perpetuate insulated cells within which some of the key princi-

works toward altering the social conditions that have formed the systems that surround the [economically] disadvantaged child and his family.

Id. at I-77.

135. See Valentine \& Stark, supra note 44, at 305; see also S.M. Miller \& Ronnie Steinberg Ratner, The American Resignation: The New Assault on Equality, Soc. PoLY. May/June 1972 , at 5.

136. See Valentine \& Stark, supra note 44 , at 305.

137. See id. at 307.

138. It is worth mentioning that a study conducted in 1970 found that Head Start's influence in the larger community was being felt, and was correlated with the degree of parental involvement present in a particular Head Start center. Cf. O'Keefe, supra note 48, at 11 (discussing a study by Kirschner Associates, Inc., entitled $A$ National Survey of the Impact of Head Start Centers on Community Institutions).

139. See id. at 7.

140. See id. at 9.

141. Id. at 13.

142. Essentially no additional thorough research was undertaken until the fall of 1989 , when a Silver Ribbon Panel was convened. See Report of the Silver Ribbon PaNel, supra note 69. 
ples of a participatory or "dialogic" community143 are practiced. The question these developments raise is how, during its first decade of operation, Head Start managed to avoid the development of rigid hierarchical structures so characteristic of other agencies within the welfare bureaucracy, and how, in more recent times, it has managed to retain the participatory norms that did arise during its early history. The answers to these questions, in turn, provide the starting point for a fuller analysis of the conflict between the local culture found within many Head Start centers and conventional regulatory practices like those contained within the federal confidentiality law.

\section{THE OpPoRTunities AND LIMITS OF LIBERAL Legalism: The Promise of New Jurisprudential Voices}

The ability of activists within Head Start to exploit available rhetorical and symbolic opportunities, to blunt official government policies inconsistent with local practice, and to sustain a grassroots movement for more than two decades is a remarkable story. There are three related explanations - professionalism, political reform, and gender - for this history, and each helps to clarify the nature of the conflict between daily practice within Head Start and the formal legal structure applicable to the recent substance-abuse-related activities of the Target Cities demonstration projects. Section III.A provides a brief overview of the discussion of professionalism, political reform, and gender.

This Part is also an account of the opportunities, and also the very real limits, of liberal legalism in understanding the social world and the role that law can play in resolving the conflicts that inevitably arise. A brief discussion of this topic follows a historical explanation of the vibrancy of participation and governance within Head Start programs. Finally, this Part concludes with the suggestion that critical theory, because of the diversity of its methodology and content, has much to offer in response to the vexing problems raised by Head Start's substance-abuse-related activities.

\section{A. Professionalism, Political Reform, and Gender}

The first explanation for the development and persistence of the participatory institutional values and collaborative governance

143. Joel F. Handler, Dependent People, the State, and the Modern/Postmodern Search for the Dialogic Community, 35 UCLA L. REv. 999, 1089-93 (1988) (exploring the possibility of "dialogism" in contemporary welfare agencies, in which people in "significantly unequal situations" are able to "relate to each other as equal moral agents"). 
styles still found within Head Start centers involves the absence, at least until quite recently, of an entrenched network of credentialed professionals in the early childhood education field. A key element of Head Start's organizational style is the softening of distinctions between clients and service providers, between professionals and nonprofessionals. ${ }^{144}$ In contrast to the experience of legal services agencies that shared OEO's requirement of "maximum feasible participation," 145 parents and their advocates within Head Start did not face extensive staff resistance. ${ }^{146}$ Moreover, many Head Start personnel have been recruited from the ranks of Head Start parents, and the "career ladder" approach to staff training has helped to close the distance between professionals, paraprofessionals, and parents participating as volunteers. ${ }^{147}$

Interestingly, the development of this more participatory ethic within Head Start occurred during a period in which the socialwork profession was distancing itself from its historical relationship with social-welfare agencies and turning its attention to a new group of middle-class clients. ${ }^{148}$ As this trend away from community-oriented service and reform and toward a more individualistic and psychodynamic social-work practice gained momentum, it created something of a vacuum within institutions that served the poor. In many instances, this vacuum was filled by the agents and technicians of a developing welfare bureaucracy. ${ }^{149}$ In the case of Head Start, on the other hand, a more participatory model emerged in which staff and clients stood together in a shared institutional space. ${ }^{150}$

144. See supra text accompanying notes $44-51$.

145. EARL Johnson, JR., Justice AND Reform: The Formative Years of the OEO Legal Services Program 108-12 (1974).

146. See id.; see also Marc Feldman, Political Lessons: Legal Services For the Poor, 83 GEo. L.J. 1529, 1541-42 (1995). It should be pointed out that in the early years an entrenched group of professionals, local teachers' groups and boards of education, did resist client involvement in decisionmaking. See supra text accompanying note 126.

147. See supra text accompanying notes $44-49$.

148. For a good description and critique of this trend, see O. Gursslin et al., Social Class and the Mental Health Movement, 7 Soc. ProBs. 210 (1959). For another discussion, see Nathan E. Cohen, A Social Work Approach, in Social Work AND Soctal Problems 362 (Nathan E. Cohen ed., 1964).

149. See Simon, supra note 53 (setting out a theory of bureaucracy within social welfare institutions characterized by "proletarianized" front-line workers, rigid rules, and a management elite).

150. This characterization is based upon the historical accounts cited above, see, e.g., Midco Educ. Assocs., supra note 45; ProJect Head Start, supra note 44, as well as my own observations working with a number of Head Start centers beginning in 1991. Professor Lucie White is currently engaged in an ethnographic study of parent governance in Head Start. I expect that her findings will be consistent with my own experience. See White, Client Involvement, supra note 46. 
A second explanation for Head Start's distinctive internal ethos is that its failure to develop a more outward-directed reform agenda - a reform agenda focused on wider institutional change ${ }^{151}$ - understandably softened the impression that Head Start was likely to unsettle established social and political arrangements in the communities it served. Here it is worth recalling that the most intense battles involving Head Start arose over questions of parental governance when local school boards perceived a threat to their policymaking authority. ${ }^{152}$ Outside of the public education arena, which was the sphere of public policy most closely associated with Head Start's activities, however, those in positions of power expressed relatively little concern.

The one significant exception to this general attitude of indifference only helps to reinforce the basic point. By far, the most controversial Head Start program over the years was the ChildDevelopment Group of Mississippi (CDGM). ${ }^{153}$ From its inception, the leaders of this program were deeply involved in the civil rights struggle occurring in Mississippi. Activists throughout the state saw Head Start as an organization capable of leading their effort to undermine the white power-structure in the state. ${ }^{154}$ As Sargent Shriver, then Director of OEO, has told the story:

Down in Mississippi, there were a lot of people who looked upon Head Start and CDGM as a means of transferring substantial sums of money directly to the black people of the state for the first time - a way of empowering black people, and of mobilizing them on a statewide basis. ... The money sent from Washington directly to CDGM to organize Head Start programs all over Mississippi was a mandate to go into every community in the state and organize the people politically through Head Start. As a consequence, what had been looked upon in the beginning by some in Mississippi, especially white people, as a harmless social program immediately became hostile intervention by the federal government, bent upon upsetting the social structure of Mississippi, specifically white supremacy. CDGM became a spearhead of the civil-rights movement in Mississippi, and therefore bore

151. See Valentine \& Stark, supra note 44 , at 308 . As a general matter, critics charged that all of the OEO programs placed "too much emphasis on changing people" and "not enough emphasis" on "institutional change." Mroco EDuc. Assocs., supra note 45, at I-48. For a full discussion of this victory of liberalism over radicalism, see FRANCEs Fox PIVIN \& Richard A. Cloward, Regulating the Poor: The Functions of Public Welfare (1971).

152. See supra text accompanying note 126.

153. For a powerful account of this movement, see Polly Greenberg, THE DeVIL Has Slippery Shoes: A Biased Biography of the CHILd DevelopMent Group OF MissisSIPPI (1969).

154. See Shriver, supra note 86 , at 62. 
the major brunt of the opposition of the white community in the state, and of its congressmen and senators in Washington. ${ }^{155}$

After only its first year of operation, political opposition to CDGM, both locally and in Washington, led to the elimination of its funding. In Washington, opponents, including Senator John Stennis, had instituted a financial investigation and placed pressure on OEO to micromanage the activities underway in Mississippi. In order to avoid further political fallout that he believed might jeopardize other OEO programs, Shriver terminated CDGM's federal funding and encouraged the formation of an alternative program in Mississippi that was willing to operate Head Start without an explicit political agenda. ${ }^{156}$

\section{B. Liberal Legalism and Its Limits}

The third, and most subtle, explanation for Head Start's organizational structure and its insulation from significant intervention by the welfare bureaucracy, is that it has always been a program for and by poor women - many of them women of color - and their children. Due to the nature of the population Head Start serves and the nature of its agenda, the unconventional efforts of those involved in structuring and developing this project have not generally drawn the attention of policymakers. From the perspective of those outside of Head Start, this effort has been, at most, self-help on the part of poor women and their children, hardly a matter of great concern to those in positions of greater privilege and power. ${ }^{157}$

\section{Id.}

156. See id. at 63.

157. It is one thing to talk about the relative inattention of policymakers to the lives of poor women and their children, it is quite another to speak of the fierce interest shown by those same policymakers toward the problems posed by impoverished women and children. In the former instance, the perspective is that of families living in poverty; in the latter it is the perspective of others whose interests may be affected for the worse by the fact that some number of women and their children live at the very margins of society. Valerie Polakow has explained this distinction in the following terms:

The way in which we choose to talk about poverty - as a social problem, an urgent issue in need of attention, a dilemma, a menace, a threat to the society, a cost to the taxpayer, or, as one of my colleagues once stated, just "another variable of development" - creates a noise, followed by echoes that locate the invisible lives of poor women and their children. They, living out there in the unnamed landscapes, periodically swell into visibility as the poverty issue is targeted for public attention by competing political agendas. Poverty talk, however, is always a discourse about them. As they get closer and their proximity makes us uncomfortable, we clamor for laws to contain them, to regulate their space in relation to ours. ... Their otherness places us "at risk"; yet it is we who have named them. We have both invented and named poverty.

Valerie Polakow, The Other Motherhood: The Landscape of Single Mothers In Poverty, in Lives on the Edge (1993), reprinted in Power, Privilege and LaW: A Civil Rights READER 524-25 (Leslie Bender \& Daan Braveman eds., 1995). 
This harbored history of inattention is related to the absence of an entrenched group of professionals concerned about Head Start's activities, because both phenomena stem from a tendency in the dominant culture to locate "women's issues," defined here to include the care of children, within a "private" realm insulated from the larger "public" sphere. ${ }^{158}$ This distinction between public and private realms is fundamental to classical liberalism, and functions as a core element of liberal legal practice. ${ }^{159}$

158. To the extent that Head Start activities have been associated with child rearing more generally, they have been treated as occurring within a domestic environment in which both "professionalism" and the legal regulation ordinarily intended for "public" activities is thought to be inappropriate or unnecessary. As Frances Olsen has made clear, it has been characteristic of the liberal tradition to organize social data into dualist categories, like public-private, in which each pair is made up of a superior male category and an inferior female one. Frances Olsen, The Sex of Law, in The Polmos of Law: A Progressive Critioue 453-54 (David Kairys ed., rev. ed. 1990); see also Kimberle Williams Crenshaw, Race, Reform, and Retrenchment: Transformation and Legitimation in Antidiscrimination Law, 101 HARV. L. REV. 1331, 1373 (1988). While some feminists have accepted this dualist vision of social life, arguing instead for a nonhierarchical arrangement of the categories in order to overcome women's subordination, see, e.g., CARol GILligan, IN A DifFerent VoICE: Psychological Theory and Women's Development (1982); Carrie Menkel-Meadow, Portia in a Different Voice: Speculations on a Women's Lawyering Process, 1 BERKELEY WOMEN's L.J. 39 (1985). Olsen urges a more contextual form of analysis in which the dualisms themselves are challenged in specific concrete instances of gender oppression. Olsen, supra.

159. For a general discussion and critique of this basic distinction, see Alan Freeman \& Elizabeth Mensch, The Public-Private Distinction in American Law and Life, 36 BuFf. L. REv. 237 (1987); Duncan Kennedy, The Stages of the Decline of the Public/Private Distinction, 130 U. PA. L. REv. 1349 (1982).

It should be noted that classical liberal theory and liberal legalism, though related, are not the same. Classical liberal theory refers to a tradition of liberal political philosophy with roots going back to Jeremy Bentham and John Stuart Mill. For a good introduction to the foundations of liberal political theory, see MiCHAEL, J. SANDEL, LIBERALISM AND THE LIMITS OF Justice 1-65 (1982); Joseph W. Singer, The Legal Rights Debate in Analytical Jurisprudence from Bentham to Hohfeld, 1982 Wis. L. REV. 975, 980. Liberal legalism, as that phrase is employed in this text, refers to a modified form of classical legalism that began to develop in the early decades of the twentieth century. See Morton J. Horwitz, The Jurisprudence of Brown and the Dilemmas of Liberalism, 14 HARV. C.R.-C.L. L. REv. 599 (1979). Classical legalism was the dominant jurisprudence during most of the nineteenth century. Its central features were an emphasis on individual autonomy and independence from the coercive authority of the state, a belief in contractual exchange as a just distributive mechanism, and a reliance on the private law rules of contract, tort, and property. See William H. Simon, The Invention and Reinvention of Welfare Rights, $44 \mathrm{MD}$. L. REv. 1, 9-10 (1985). Following the Supreme Court's decision in Brown v. Board of Education, 347 U.S. 483 (1954), and culminating with the publication of Charles Reich's The New Property in 1964, this classical legal tradition underwent what some have called a "legal rights revolution." Handler, supra note 143, at 1019. The resulting liberal legalist jurisprudence retained many of the features of classical liberalism, including an emphasis on individual autonomy and on property rights, but this liberal jurisprudence expanded the notion of property to include entitlements individuals could expect from government as well as from other private actors. As such, a "wide range of social harms ... [were] converted into protectable legal rights." Id. at 1018. Among these newly discovered legal interests, a right to insist upon the confidentiality of alcohol and drug treatment information is typical. For a thorough discussion of this liberal jurisprudence, see Simon, supra, at 23-28. 
According to the liberal paradigm, society is comprised of rational, egoistic individuals. ${ }^{160}$ When citizens interact with one another in the public sphere, classical liberal theory assumes that they will pursue their self-interested objectives by way of arms-length dealings. ${ }^{161}$ In its pure form, classical liberal theory assumes that relatively unfettered self-interested interactions within the public sphere will generate the most good for society in the aggregate. ${ }^{162}$ This assumption is central to liberal legalism, in which the concept of contractual exchange is the norm for public interaction. ${ }^{163}$

Within classical liberalism's private realms, by contrast, the norms of affiliative relationship and regard for others replace the mechanism of arms-length bargaining between autonomous individuals. In the private sphere, people are presumed to engage with family and friends in ways that create and respect interpersonal vulnerability, foster nurturing and supportive relationships, and rely upon trust and temper self-interest. ${ }^{164}$

The role of law in the liberal conception is formed by reference to this strong dichotomy between the public and private realms. ${ }^{165}$

160. See Simon, supra note 159 , at 9-10.

161. See generally RICHARd A. POSNeR, THE ECONOMIcs OF Justice (1981); see also Robin West, Authority, Autonomy, and Choice: The Role of Consent in the Moral and Political Visions of Franz Kafka and Richard Posner, 99 HARv. L. Rev. 384 (1985); Richard A. Posner, The Ethical Significance of Free Choice: A Reply To Professor West, 99 Harv. L. REv. 1431 (1986).

162. See Richard A. Posner, Economic Analysis of Law 497-502 (2d ed. 1977).

163. See Lesnick, supra note 85, at 423; Deborah L. Rhode, Feminist Critical Theories, 42 StAN. L. REv. 617, 628 (1990); Singer, supra note 159, at 983.

164. The United States Supreme Court has opined that:

[C]hoices to enter into and maintain certain intimate human relationships must be secured against undue intrusion by the State because of the role of such relationships in safeguarding the individual freedom that is central to our constitutional scheme... .

....

... Moreover, the constitutional shelter afforded such relationships reflects the realization that individuals draw much of their emotional enrichment from close ties with others.

Roberts v. United States Jaycees, 468 U.S. 609, 617-19 (1984); see also Ronald Dworkin, Liberalism, in Public aNd PRIVATE MORALITY 113 (Stuart Hampshire ed., 1978); Rhode, supra note 163 , at 628 .

165. Any effort to speak about the public-private distinction is bound to run into terminological confusion. Some writers have suggested that the construct may have no meaning at all, see, e.g., Kennedy, supra note 159, and others have argued that the very instability of the boundary between public and private life serves as a principal occasion for the operation of constitutional adjudication, see, e.g., Louis M. Seidman, Public Principle and Private Choice: The Uneasy Case for a Boundary Maintenance Theory of Constitutional Law, 96 YALE L.J. 1006 (1987). Perhaps, some of the confusion stems from the fact that writers often employ the public-private language to evoke a distinction between governmental and nongovemmental spheres of influence or activity. Pursuant to this usage, it might be thought that the activity of simple contracting between nongovernmental business entities occurs within the private sphere. As scores of writers have made clear, however, even simple contracts take on a special meaning in law because of the availability of government-sponsored enforcement mechanisms that include forums for the litigation of disputes and authority for the execution 
In the most general terms, liberal legalism seeks to facilitate interactions between individual citizens by protecting private property and enforcing contractual obligations, and it seeks to protect individuals' freedom to engage in autonomous choice by insulating private life from the intrusion of overzealous government officials. The law is regarded as capable of accomplishing both of these tasks through the application of formal, abstract rules that limit official discretion, carve out zones of privacy, and foster free choice. ${ }^{166}$

The lack of participation in Head Start by professionals, however, together with the relative insulation of this enterprise from the larger political sphere, has contributed to the development of local cultures that are fundamentally inconsistent with the liberal vision of a public institution. ${ }^{167}$ Parents, teachers, and administrators tend not to interact at arms-length, and tend not to rely on formal procedural mechanisms in order to resolve disputes and form policy. Instead, the various actors within these "communities"

of judgments. See, e.g., Singer, supra note 159, at 986-93. A more satisfactory approach, which takes account of a great deal of the confusion inherent in the public-private dichotomy, has been offered by Professor Seidman, who argues that the distinction is best understood in terms of three "interlocking dilemmas." The first dilemma treats the tension between the "universalist" and "particularist" values we all hold, the second involves our competing interests in governmental intervention and libertarianism, and the third concerns the relationship between our simultaneous impulses toward openness and secrecy. Seidman, supra, at 1007. Although he is not explicit about this point, it would seem that a good deal of the instability in the public-private distinction, which takes place along the three dimensions Seidman sets out, is due to the tendency of liberal thought to regard individuals as autonomous and presocial. See, e.g., SANDEL, supra note 159. Within that frame of reference, it makes some sense to talk about a clear divide between configurations of autonomous individuals that are open and universalist, like a meeting of the local school board or the U.S. Congress, and those that are private and particularistic, like a family dinner at Thanksgiving. If, on the other hand, one regards individuals not as "fixed entities defined prior to and independent of social relationships," but as dynamic and contingent, as plastic and perpetually in a state of redefinition as they negotiate social interaction, Meir Dan-Cohen, Responsibility and the Boundaries of the Self, 105 HARv. L. REV. 959, 961 (1992), then talk of mutually exclusive public and private spheres becomes incoherent. Moreover, a legal regime that insists upon treating individuals as fixed and presocial and that organizes itself into public and private domains, is destined, by virtue of its failure to recognize an essential nexus between individuals and groups, between the public and the private, "to constrict the self's boundaries and to encourage the enactment of a reduced and shrivelled self." Id. at 962 . It is this reduced or shrivelled sense of self that I refer to infra as an unauthentic, alienated legal subject. See infra text accompanying notes 177-81.

166. Handler, supra note 143, at 1018; Steven Shiffrin, Liberalism, Radicalism, and Legal Scholarship, 30 UCLA L. REv. 1103 (1983).

167. Head Start represents an altemative institutional model in which "locally centered institutional networks ... are managed, insofar as possible, through democratic rather than bureaucratic processes at the local level." It is, therefore, a potentially better environment for "teaching clients skills of civic involvement," for "awaken[ing] their empathy for others' concerns," and for "wider normative commitments to individual self-determination and a democratic social life." White, Client Involvement, supra note 46, at 14. For a more recent discussion indicating the complicated and multilayered kind of community this institutional form creates, see Lucie White, Ordering Voice: Rhetoric and Democracy in Project Head Start, in The RHETORIC OF LAW 185 (Austin Sarat \& Thomas R. Kearns eds., 1994). 
are more likely to engage one another out of a sense of common purpose and to find solutions within the context of their ongoing relationships. ${ }^{168}$

The federal confidentiality laws and regulations, on the other hand, are squarely within the liberal legal tradition. They presume a regulated setting in which individual clients will need formal legal protection in order to ward off the incursions of overzealous public actors. Thus, they confer upon substance-abuse patients a set of legal rights designed to safeguard each individual's freedom of action by carving out a zone of privacy. The laws presume that treatment providers, in contrast, are arbitrary and unreliable bureaucrats in need of the restraint provided by clearly delineated legal rules. Under this scheme, the application of formal procedures governing the dissemination of confidential information vindicates an individual patient's right to privacy. ${ }^{169}$

Unfortunately, these formal confidentiality rules do not fit well within the day-to-day operation of many Head Start centers. This disjunction can best be understood, and, perhaps, managed, by employing the work of critical theorists who have attempted to analyze, critique, and depart from the basic paradigm of liberal legalism. ${ }^{170}$ Fundamental to these alternative accounts is a description of desire, preference, and action directly at odds with the classical liberal notion of autonomous individualism. Rather than viewing preferences as intrinsic and presocial, much critical theory starts with the premise that individual choices are formed within a social context. ${ }^{171}$ Critical theorists posit that an individual's web of affiliations and group identifications constructs her identity within the larger culture. Moreover, while classical liberalism regards social exchanges as static interactions between fixed, atomistic entities, the alternative critical account describes social intercourse as a fluid, continual process of self-definition and redefinition. ${ }^{172}$ Individual agendas are not comprised of privately developed desires and preferences brought into the public sphere by egoistic selves;

168. See supra Part II.

169. See supra Part I.

170. While reference is made here to "critical theorists," what follows is drawn from a number of related jurisprudential currents, including critical legal studies, critical feminism, and critical race theory.

171. See generally Mark Kelman, A Guide to Critical Legal Studies 66-67 (1987); Mark Tushnet, Critical Legal Studies: An Introduction to its Origins and Underpinnings, $36 \mathrm{~J}$. LEGAL EDUC. 505, 506-09 (1986).

172. See Kathy E. Ferguson, The Feminist Case Against Bureaucracy 196 (1984); see also SANDEL, supra note 159; Dan-Cohen, supra note 165. 
rather, individual lives gain meaning within the rich context of ongoing social discourse. 173

An important contribution of critical theory has been its attention to the role of formal legal rights within liberal legalism. Early critical legal studies writers argued that the pursuit of an individualrights-based agenda might serve to disempower those in society who are already most vulnerable. ${ }^{174}$ A rights-based approach not only legitimizes structural forms of inequality, ${ }^{175}$ but also undermines opportunities for collective engagement and political activity. ${ }^{176}$

For present purposes, however, the most important element of this postrealist critique ${ }^{177}$ is the claim that a liberal regime of individual rights transforms concrete social settings into abstract legal formulations. ${ }^{178}$ In part, this process of abstraction is necessary given the level of generality at which uniform legal prescriptions operate. ${ }^{179}$ In other respects, it is a function of liberal legalism's inability to manage human relationships within a larger social context. The abstraction of liberal legalism not only disables attempts to resolve social conflicts, but also reduces individuals to categorical types. ${ }^{180}$ Individual human actors embedded in a specific and

173. Critical scholars have offered more than a complicated account of "public" life; they have also challenged classical liberalism's rather simplified picture of the "private" sphere. In the place of an idealized version of "family life" in which the state rarely if ever intrudes, government policies with respect to reproductive choice, child care, marital property, and welfare are described as exerting a powerful influence on the ways in which "families" arrange themselves. See, e.g., Frances E. Olsen, The Myth of State Intervention in the Family, 18 U. MiCH. J.L. REF. 835 (1985). In addition, a number of writers have pointed out that decisions on the part of the state not to intervene in "private" matters have also had a profound impact on the lives of those made vulnerable by larger societal processes. Thus, noninterventionist policies with respect to marital rape and other forms of domestic violence clearly have had the effect of legitimating abusive relationships between people of unequal power. See id.; see also Rhode, supra note 163 , at 631.

174. See, e.g., Peter Gabel \& Duncan Kennedy, Roll Over Beethoven, 36 StaN. L. Rev. 1, 33 (1984).

175. See Alan Freeman, Antidiscrimination Law: A Critical Review, in THE Polrtics OF LAw, supra note 158, at 96; Tushnet, supra note 171, at 516.

176. Gabel \& Kennedy, supra note 174, at 33-40.

177. See Andrew Altman, Legal Realism, Critical Legal Studies, and Dworkin, 15 PHrL. \& PuB. Afr. 205 (1986).

178. See Jurgen Habermas, Law as Medium and.Law as Institution, in DILEMMAS OF LAW IN THE Welfare State 203, 210 (Gunther Teubner ed., 1986).

179. Rhode, Olsen, and other critical theorists have "not[ed] that rights discourse cannot resolve social conflict but can only restate it in somewhat abstract, conclusory form." Rhode, supra note 163, at 633.

180. In describing the impact of the welfare bureaucracy upon social life, Joel Handler has explained that

[p]reviously, socialization - moral in the family, pedagogical in the schools - took place through communicative action. Legalization supplants this communicative context with legal norms; relations become formalized; family members, pupils, teachers, and 
unique web of affiliations and marked by a specific and unique life history are reconfigured as "legal subjects" - as categorical types alienated one from another and from their socially situated selves. ${ }^{181}$

Several associated factors drive this process of increasing abstraction, and each can be identified in the application of the federal confidentiality rules to Head Start's substance-abuse project. The first is liberal legalism's preoccupation with individual entitlement. Because formal legal rights are defined by reference to individuals and conferred upon atomistic legal subjects, the process of vindicating those rights necessarily treats the holder of those rights as a decontextualized actor. ${ }^{182}$ As noted earlier, in the Head Start setting the liberal perspective has resulted in confidentiality regulations designed to protect the privacy of individual patients. The regulations do not, on their face, allow the treatment provider to regard a chemically dependent individual's family as "the patient" for purposes of sharing important information within the program. ${ }^{183}$ The success of Head Start's interventions with substanceabusing parents, by contrast, depends upon the ability of classroom teachers, parent liaisons, mental health workers, and others to engage as a team with the adult addict and her children and, perhaps, other family members and friends as a constellation of related people whose problems are deeply intertwined and whose interdependence must be acknowledged to fashion effective solutions. ${ }^{184}$

Similarly, the federal confidentiality provisions reflect liberal legalism's abhorrence of official discretion. ${ }^{185}$ These provisions rely upon formal substantive rules prohibiting the disclosure of patientidentifying information and strict procedural requirements gov-

parents now encounter each other as legal subjects. The relationships are converted to the medium of law but the abstractness of law applies without regard to the specific needs and interests of the persons involved.

Handler, supra note 143, at 1045; see also Peter Gabel, The Phenomenology of Rights-Consciousness and the Pact of the Withdrawn Selves, 62 TEXAs L. REv. 1563 (1984).

181. See Gabel, supra note 180; see also Habermas, supra note 178, at 211; Handler, supra note 143 , at 1044 .

182. See Horwitz, supra note 159, at 604 (describing a "political and legal culture of individualism that defines a problem exclusively in terms of the rights of individuals" tends to "strip individuals of their group identity"); see also Mark Tushnet, An Essay on Rights, 62 TEXAs L. Rev. 1363, 1382-83 (1984).

183. See supra text accompanying notes 55-56.

184. See supra text accompanying notes 57-61.

185. See Simon, supra note 159 , at $27-28$ (the vision of public administration within the "New Property Jurisprudence" includes "formality," "bureaucratization," and the "proletarianization" of staff); see also Handler, supra note 143, at 1060; Charles Reich, The New Property, 73 YALE L.J. 733, 783-85 (1964). 
erning patient consent, internal communications, and the like. This effort to limit the range of discretion available to treatment personnel regarding the communication of sensitive information has the potential to impair the "communicative context" within Head Start. ${ }^{186}$

Unfortunately, the conventional picture of individual patients enmeshed in a bureaucratic apparatus and in need of explicit legal protection against arbitrary official power fails to capture daily practice within many Head Start centers. In place of powerful and distanced bureaucrats, Head Start parents are more likely to encounter staff members operating in a distinctly antibureaucratic fashion, with little hierarchical distance. Indeed, though the liberal legalist premises of the confidentiality regulations assume a divergence of interest between patients and program staff that may jeopardize the well-being of disempowered patients in the absence of legal regulation, the history of and actual behavior in many Head Start centers suggest a strong commonality of interest and experience among parents and staff. This commonality helps to facilitate - and often encourages - interactions based upon trust and care. ${ }^{187}$ To the extent that this programmatic picture of human actors known to and engaged with one another is accurate, the application of formal legal prescriptions and procedures may set off a dynamic capable of undermining empathy and cooperation, and may lead to increased hierarchy. ${ }^{188}$

A final element of liberal legalism reflected in the confidentiality laws and regulations is its assumption that public life is most productive when it operates on the basis of individual freedom of choice. According to the liberal paradigm, society is made up of egoistic, self-interested decisionmakers. The way to create the most good for the greatest number of people is to encourage arms-length transactions between parties seeking to maximize their individual preferences. As Robin West has explained: "A law which either facilitates or mimics consensual transactions between freely choos-

186. Handler, supra note 143, at 1045.

187. This empirical observation corresponds with the theoretical descriptions offered by Annette Baier. See Annette Baier, Trust and Antitrust, 96 ETrIcs 231 (1986). Baier's work is a systematic effort to show how trust - as opposed to contract - operates in relationships between people who hold unequal shares of power. Her argument is that parties are assisted in trusting one another, and in reposing confidence, when they act to further a "common good." Id. at 242-46.

188. See Handler, supra note 143, at 1059. 
ing individuals is a good law on this model, while a law which frustrates such transactions is a bad law."189

The centrality of this principle of liberalism is apparent in the federal regulations' extensive use of individual patient consent as a mechanism for regulating the availability of confidential information. ${ }^{190}$ Once again, however, the poor fit between the law's essential animating premise - that individuals only consent to transactions that increase their welfare - and the concrete experience of those whose consent is to be requested, especially women who may be inclined to "consent" to transactions in order to increase the welfare of others, makes the application of this law to the Head Start context problematic.

Robin West's work has explored the consequence for women of liberal legalism's persistent use of consent as the pivot around which daily transactions occur. West's methodological approach is "phenomenological," for she initiates her analysis with women's actual experiences and desires rather than with an abstract commitment to freedom or equality. ${ }^{191}$ By grounding her analysis in the concrete data of women's internal lives, West is able to suggest that liberalism's core normative claim, "that human beings consent to transactions in order to maximize their welfare," 192 may in fact be a false description, at least insofar as women are concerned.

Counterposed against the "liberal self" engaged in consensual transactions in order to vindicate self-interest, West offers up the "giving self," which she describes as a characteristically female persona who "consents" to transactions not necessarily in her interest in order to maximize the welfare of others. ${ }^{193}$ West makes no claim that the difference between the "liberal male self" and the "giving female self" is intrinsic; rather, she suggests a "causal hypothesis" based upon the pervasive threat of sexual violence all women face. ${ }^{194}$ Her argument, in essence, is that women respond to the ever-present potential of violent male sexuality by redefining themselves as "giving selves," in order to manage the constant fear of being violated. "Most simply, a woman will define herself as a 'giving self' so that she will not be violated. She defines herself as a

189. Robin L. West, The Difference in Women's Hedonic Lives: A Phenomenological Critique of Feminist Legal Theory, 3 Wis. WoMEN's L.J. 81, 91 (1987).

190. See supra text accompanying notes 29-34.

191. West, supra note 189 , at $87-88$.

192. Id. at 92.

193. Id. at $90-93$.

194. Id. at 94. 
being who 'gives' sex, so that she will not become a being from whom sex is taken." 195

Importantly, the danger that energizes a woman's transformation into a "giving self" is likely to vary considerably from one person to the next, and is likely to be experienced differently depending upon a particular woman's other characteristics. ${ }^{196}$ West's phenomenological methodology and feminist voice is powerful precisely because it builds theoretical insight out of the concrete data of internal experience. Because this descriptive enterprise must aggregate the experiences of individual women, however, it raises the possibility of homogenizing or "essentializing" all women's experiences. ${ }^{197}$ Ironically, one strategy for managing this methodological tension is both to broaden and particularize the account.

The broadening may be accomplished by fitting West's "causal hypothesis" about the effects on women of pervasive male violence into a framework offered by radical feminists' observations about power and hierarchy in general. ${ }^{198}$ West believes that women reconstitute themselves as "giving selves" in order to control the persistent fear of acquisitive male sexuality. This fear is invisible to men because the danger from which it derives is not part of men's experience and because the very act by women of managing the fear disguises its true nature. ${ }^{199}$ In the end, this invisibility inflicts a double injury upon women: it not only hides the pain of a diminished sexual autonomy, it also obscures the ways in which liberalism's "ethic of consent" 200 potentially disadvantages women in all

195. Id. at 96.

196. See Kimberle Williams Crenshaw, Demarginalizing the Intersection of Race and Sex: A Black Feminist Critique of Antidiscrimination Doctrine, Feminist Theory and Antiracist Politics, 1989 U. Chr. Legal F. 139; Marlee Kline, Race, Racism, and Feminist Legal Theory, 12 HARV. WOMEN's L.J. 115 (1989).

197. Rhode, supra note 163, at 624-25. See generally ElizABETH V. SpELMAN, INESSENtial Woman: Problems of Exclusion in Feminist Thought 187 (1988). Patricia Williams has offered an interesting alternative critique of "consent" that does not rely upon claims with respect to the social position of all women. See Patricia J. Wrlliams, The ALCHEMY OF RACE AND Rights 32-34 (1991).

198. See, e.g., Catharine MacKinnon, Feminism, Marxism, Method and the State: An Agenda for Theory, 7 Signs 515 (1982); Catharine MacKinnon, Feminism, Marxism, Method and the State: Toward Feminist Jurisprudence, 8 Sians 635 (1983); Nadine Taub \& Elizabeth M. Schneider, Perspectives on Women's Subordination and the Role of Law, in Polrmcs of LAW, supra note 158, at 117.

199. See West, supra note 189 , at $94-97$.

200. Id. at 92 . 
of those settings in which they consent to transactions from a position of subordination. ${ }^{201}$

The point here is speculative, but of critical importance to this argument. If West is correct in her description of how women respond to the pervasive danger of sexual violence, it is reasonable to conclude that many women will respond in a similar fashion to other threatened incursions of their autonomy by those who hold positions of superior power. Thus, it is possible that a woman who has reconstituted herself as a "giving self" out of fear of male violence, and who finds herself in an institutional setting in which other demands are being made upon her by bureaucrats acting with official authority, will also "consent" to those demands without regard to her self-interest.

If this speculation holds weight, then the role of patient consent as a central element within the federal confidentiality laws becomes problematic. $^{202}$ In the context of Head Start, the patient whose consent is to be obtained is likely to be a poor woman of color whose position in society is marked by a complex multiplicity of "selves." 203 Whether she will be able to grant consent in a way that honors her self-interest will turn on a range of factors, including the social position of the person requesting her consent, the system of power relationships present, and the alternatives available to her in light of those power dynamics. ${ }^{204}$

201. It is unclear whether West means to apply her analysis this broadly, to include "consensual" transactions that have nothing directly to do with sexuality. There is language in the article, however, to support this fuller application.

In a deep sense (too deep: she tends to forget it), this transformation is consensual: she

"consents" to being a "giving self" - the dependent party in a comparatively protective relationship - for self-regarding liberal reasons; she consents in order to control the danger both inside and outside of the relationship, and in order to suppress the fear that danger engenders. Once redefined, however, and once within those institutions that support the definition, she becomes a person who gives her consent so as to ensure the other's

happiness (not her own) ... and ultimately so as to obey the other's commands. In other words, she embraces a self-definition and a motive for acting which is the direct antithesis of the internal motivational life presupposed by liberalism.

Id. at 96-97 (emphasis added).

202. Perhaps the assumption that drug or alcohol abuse patients are capable of protecting themselves through informed consent makes sense when applied to middle-class, white males. Perhaps it even makes sense when applied to middle-class, white women who, though subordinate in terms of gender relationships, may feel no particular coercion in their interactions with a treating physician, social worker, or drug counselor.

203. Angela P. Harris, Race and Essentialism in Feminist Legal Theory, 42 STAN. L. REv. 581,584 (1990).

204. See Joan C. Williams, Deconstructing Gender, 87 Mrch. L. Rev. 797, 836 (1989). As noted earlier, a relatively nonhierarchical organizational structure characterizes many Head Start centers. See supra Part II. Nevertheless, to the extent that any power differentials are present in the interactions between parents and staff, the kinds of distortion described by West with respect to consent are also likely to occur. 
The patterns of subordination that shape women's experiences intersect with patterns of subordination based upon race, class, and sexual orientation. ${ }^{205}$ West's critique of liberal legalism has great explanatory power because it makes clear that arms-length consensual transactions do not necessarily yield satisfactory outcomes, especially when the transacting parties are of unequal power. West's work on consent makes plain the partial and contingent nature of individual "free" choice. This recognition of the socially constructed nature of human wants and desires will require those interested in legal reform to adopt what some have termed a "contextualized" approach, in which the material circumstances and interior lives of those subject to a given legal regime are more fully considered.206

\section{The Promise of Critical Theory and Practice}

Within the Head Start setting, the question is how to arrange relationships among parents and staff so as to encourage a process that empowers participants and helps them "to construct themselves in a society that [has] denied them full selves."207 More particularly, the question is how, if at all, the law should be employed in Head Start communities to help manage the dissemination of highly charged information about the alcoholism or drug addiction of parents whose lives are situated within a complex web of overlapping roles and relationships.

One approach, which has been implied in the above critique of liberal legalism, would be to minimize the influence of individualistic, rights-based prescriptions. This approach would recognize the disruption and alienation likely to flow from rigidly conferring a right to privacy upon individuals. Instead of presuming the authenticity of individual patient consent and the societal value of selfinterested, arms-length bargaining, parents in consultation with others with whom they have genuine, engaged relationships would

205. See Crenshaw, supra note 196.

206. In practice, this call for "contextualized" work means that judgments about how best to proceed at a given decisional moment should be made on the basis of actual social practice, as fully described and revealed as possible. Central to this process of "locat[ing] judgment within the patterns of social practice," Rhode, supra note 163, at 626 , is the use of a narrative methodology. Storytelling is a means for grounding the work of law and legal theory in the daily lives of those whose experiences might otherwise be treated as marginal. See, e.g., Patricia Cain, Feminist Jurisprudence: Grounding the Theories, 4 BERKELEY WOMEN's L.J. 191 (1990); Leigh Leonard, A Missing Voice in Feminist Legal Theory: The Heterosexual Presumption, 12 WOMEN's Rights L. REP. 39 (1990); Mari J. Matsuda, Public Response to Racist Speech: Considering the Victim's Story, 87 MrCH. L. REv. 2320 (1989).

207. Harris, supra note 203, at 613. 
make choices about the handling of sensitive information. Staff would be treated, and expected to behave, not as distant bureaucrats but as partners in a healing process. Rather than relying upon legal entitlements to confidentiality to encourage substance-abusing parents to seek help, staff members and other parents would build upon human connections already in place within the Head Start center as the primary means by which to overcome the denial inherent in alcoholism and other forms of drug addiction. ${ }^{208}$

A review of the small but growing literature addressing women with alcohol and other drug problems helps to shed some light on why such an approach might make sense in the case of the Head Start substance abuse initiative. This literature suggests that women alcoholics and addicts tend to present different clinical characteristics than their male counterparts, and tend to respond differently than men to traditional forms of treatment. ${ }^{209}$ These differences are significant because the statutes and regulations governing the confidentiality of treatment records presume treatment facilities geared toward the characteristics and needs of male substance abusers. ${ }^{210}$ Most of the parents who receive services at Head

208. See generally Margaret H. Bean, Denial and the Psychological Complications of Alcoholism, in Dynamic Approaches to the Understanding and Treatment of AlcoHoLISM 55 (Margaret H. Bean \& Norman E. Zinberg eds., 1981).

Recognizing that liberal practice maintains an overly rigid distinction between the public and private realms, this approach might rely upon a process not unlike the feminist methodology of "consciousness-raising" to help participants understand "the social dimension of individual experience and the individual dimension of social experience." Elizabeth $\mathrm{M}$. Schneider, The Dialectic of Rights and Politics: Perspectives from the Women's Movement, 61 N.Y.U. L. REv. 589, 603 (1986). The goal of this group work might be to assist individual parents to see that their "private" struggles associated with drugs or alcohol are likely to be shared by others in the group, and that through their empathic support for others they might be enabled to assert increased control in their own lives. Employing a methodology in which "risk-taking and vulnerability [are valued] over caution and detachment," in which "[h]onesty is valued above consistency, [and] teamwork over self-sufficiency," Katharine T. Bartlett, Feminist Legal Methods, 103 HARv. L. Rev. 829, 864 (1990), this approach might well hold greater promise for assisting addicted Head Start parents than an undertaking structured around the liberal premises of the federal confidentiality laws and regulations.

209. See generally Sheila B. Blume, Alcohol and Drug Problems in Women: Old Attitudes, New Knowledge, in Treatment Choices for Alcoholism and Substance Abuse 183 (H.B. Milkman \& L.I. Sederer eds., 1990); Peter G. Fellios, Alcoholism in Women: Causes, Treatment, and Prevention, in Alcoholism and SubStance Abuse in Spectal Populations 11 (Gary W. Lawson \& Ann W. Lawson eds., 1989); Andrea Halliday \& Booker Bush, Women and Alcohol Abuse, in Alcoholism: A GuIDE FOR the PrIMARY CARE Physictan 176 (Henrietta N. Bames ed., 1987); Linda J. Penniman \& Jacqueline Agnew, Women, Work and Alcohol, 4 Occupational MED. 263 (1989); Helen E. Ross, Alcohol and Drug Abuse in Treated Alcoholics: A Comparison of Men and Women, 13 AlcoHolism: Clinical \& Expertmental Research 810 (1989); Steven Schenker \& K. Vincent Speeg, Risk of Alcohol Intake in Men and Women: All May Not Be Equal, 322 NEw ENG. J. MEd. 127 (1990).

210. See supra section I.A. 
Start centers are women, 211 and the chief organizational features of Head Start are distinctively unlike traditional drug- and alcoholabuse treatment programs. ${ }^{212}$

Among the reported differences between men and women who are substance abusers, several are particularly relevant to a discussion of the needs of Head Start parents. Researchers and clinicians have reported that the patterns of substance abuse exhibited by addicted women tend to be related more closely to the drinking and drug-abuse patterns of their spouses or significant others than is typical for male addicts or alcoholics. ${ }^{213}$ Female substance abusers often exhibit higher levels of anxiety and depression, and lower self-esteem, than their male counterparts. ${ }^{214}$ In addition, the occurrence of family trauma, especially childhood physical and sexual abuse, has been found prevalent among substance-abusing women, ${ }^{215}$ and a strong correlation has been shown between the presence of ongoing, violent, intimate relationships and alcoholism treatment outcomes for women. ${ }^{216}$ Because of persistent and sexist stereotypes about women who abuse alcohol and other drugs, including the notion that they are especially promiscuous or sexually aggressive, ${ }^{217}$ many more women than men tend to drink and use

211. See supra section III.B.

212. See supra section I.B.

213. Thus, treatment outcomes for women often depend upon whether the patient's spouse or significant other is engaged in ongoing substance abuse. See Blume, supra note 209 , at 193.

214. One study found that $19 \%$ of the women who were alcoholic or alcohol dependent also fulfilled the criteria for a lifetime diagnosis of major depression. This figure compared with $5 \%$ of the men studied and $7 \%$ of women in the population generally. See Sheila B. Blume, Alcohol and Other Drug Problems in Women, in Substance ABuSE: A COMPRE. HENSIVE TEXTBOOK 798 (Joyce H. Lowinson et al. eds., 2d ed. 1992) (discussing Michie Hesselbrock et al., Psychopathology in Hospitalized Alcoholics, 42 ARCH. GeN. PsYCHIATRY 1050 (1985)); see also CorRIGAN, supra note 60; Linda J. Beckman, Self-Esteem of Women Alcoholics, 39 J. Stud. Alcohol 491 (1978).

215. For example, in one study, $67 \%$ of the sample of alcoholic women reported that they had been the victims of sexual abuse as children. See Brenda A. Miller et al., The Role of Childhood Sexual Abuse in the Development of Alcoholism in Women, 2 VIOLENCE \& VIC TIMS 157, 163 (1987).

216. One study of 44 female alcoholics found strong correlations between a childhood history of family violence on the one hand and violence in partner relationships as an adult and outcome of substance abuse treatment on the other. The data showed that childhood violence explained $11 \%$ of the total variance in treatment outcomes, and ongoing partner violence after treatment increased the outcome variance to $25 \%$. The author of the study concluded that "the results of the multiple regression analysis suggest that remaining with a violent partner after treatment may be most predictive of negative treatment outcome in this group of female alcoholics." Brit Haver, Female alcoholics: $I V$. The relationship between family violence and outcome 3-10 years after treatment, 75 ACTA PsYCHIATRICA SCANDINAVICA 449, 452-53 (1987).

217. See Corrigan, supra note 60 , at 63 . 
drugs in private. ${ }^{218}$ This tendency to hide their substance abuse not only makes the identification and diagnosis of women addicts more difficult, it also exacerbates the sense of guilt and shame they are likely to feel, as they internalize the same stereotypes that drive them into hiding. ${ }^{219}$

Not surprisingly, chemically dependent women who do seek treatment are more likely to be motivated to obtain help because of family pressures or health problems; men are more often pushed into treatment as a consequence of employment or criminal difficulties. ${ }^{220}$ In fact, many of the differences presented by female substance abusers as compared to their male counterparts tend to translate into different treatment needs.221. For example, clinicians report that effective treatment of women often depends on obtaining an accurate history of physical or sexual abuse or both, as well as the availability of same-gender therapy groups so that ongoing psychological effects from that abuse can be explored fully.222 Group processes focusing upon the internalized guilt and shame experienced by many sexual assault survivors, and by many chemically dependent women, ${ }^{223}$ can play a powerful role in helping participants begin to cope with a disempowering sense of isolation. The recognition that they are not alone in having experienced assaultive relationships or in struggling with alcohol and other drugs may assist some women to sort out their own responsibility for past and future choices, as well as the responsibility of others for their lives' circumstances. 224

Because the spouses or significant others of chemically dependent women may have their own alcohol or drug problems, success in treatment frequently will depend upon the effective evaluation

218. Because drinking, especially heavy drinking, is generally held to be less acceptable for women than for men, women are said to feel more stigma and shame because of society's nonacceptance of the intoxicated woman. Women are thought to differ from men because they are more likely to be lone, secretive drinkers.

Id. at 3 (citations omitted); see also Edith S. Lisansky, Alcoholism in Women: Social and Psychological Concomitants, 18 Q.J. STUD. Alcorol 588, 605 (1957).

219. See Edith S. Lisansky Gomberg, Alcoholic Women in Treatment: The Question of Stigma and Age, 23 Arcohol \& Alcoholism 507, 511 (1988); see also Blume, supra note 209.

220. See Corrican, supra note 60, at 3; Blume, supra note 209, at 188.

221. See, e.g., Brenda V. Smith, Improving Substance Abuse Treatment for Women, 24 Clearinghouse Rev. 490 (1990) (describing distinct needs of pregnant, addicted women).

222. See Blume, supra note 214 , at 794, 801-02.

223. See id. at 801; Lisansky Gomberg, supra note 219.

224. Cf. Blume, supra note 214 , at 801. 
and treatment of family members. 225 Looking past the links between chemically dependent women and their immediate partners, however, several studies have found that treatment outcomes for substance-abusing women often will turn on whether a number of other supportive relationships are available to them.226 Once again, intervention and therapeutic practices that build upon social networks that may already be in place at the Head Start center are likely to be far more effective for many women than traditional forms of treatment that are more individualistic in nature.

More broadly, the interwoven effects of pervasive sexism, poverty, and chemical dependency must be addressed if treatment is to be effective. ${ }^{227}$ The simple avoidance of sexist, heterosexist, ${ }^{228}$ and racist ${ }^{229}$ stereotypes, though an important first step, may not be a sufficient modification to the traditional forms of treatment otherwise available to many chemically dependent women in Head Start. In a recent article, Lucie White draws upon her field work to tell the story of one Head Start mother's efforts to obtain "psychic relief" from the harshness of her everyday life. ${ }^{230}$ According to White, a familiar strategy for dealing with a persistently subordinated status is to "escap[e] the world" through evangelical religion, television, daytime sleep, or drugs. ${ }^{231}$ In her interviews, White found that women like the Head Start mother she describes

225. See id. at 801; see also J.G. MacDonald, Predictors of Treatment Outcome for Alcoholic Women, 22 INTL. J. ADDICTION 235 (1987).

226. MacDonald, supra note 225. One researcher found a strong relationship between social support and the length of time women who had received treatment remained abstinent from alcohol and other drugs. See Blume, supra note 214, at 802 (discussing B.E. Havassy et al., Social Support and Relapse To Tobacco, Alcohol and Opiates, in Problems of DRUG DEPENDENCE 1987 (National Institute on Drug Abuse, Research Monograph No. 76, 1987)).

227. One expert has explained that

[s]exism and its consequences (for example: unequal societal roles, undervaluation of women's contributions to societal and family functioning, underemployment, and inadequate pay) should be explored in relationship to the experience of the chemically dependent woman. It is important that the treating professional not measure success only in terms of adjustment to the societal stereotype of the female role, because in doing so he/she may help the patient avoid confronting her feelings about individuality and independence and thereby miss the best possible opportunity to enlarge the range of conscious choices about her life. This narrow "adjustment" goal may also fail to raise self-esteem ....

Blume, supra note 214 , at 801.

228. On the special treatment needs of lesbians, see S.C. Anderson \& D.C. Henderson, Working with Lesbian Alcoholics, 30 Social WORK 518 (1985); D.L. Diamond \& S.C. Wilsnack, Alcohol Abuse Among Lesbians: A Descriptive Study, 4 J. Homosexualrty 123 (1978).

229. Some of the special treatment needs of African American women have been described in C.S. Carter, Treatment of the Chemically Dependent Black Female: A Cultural Perspective, 5 COUNSELOR 16 (1987).

230. White, supra note 12 , at 1995.

231. Id. 
know about the dangers of addictive drugs, both for themselves and their children. She concludes that "[ $t]$ hese lives are not being lost through ignorance, or carelessness, or a will to die. Rather, from [the Head Start mother's] perspective, people in her position must sometimes risk their lives in order to seek relief from their pain."232 The clear message here, and the message in much of the literature on the special treatment needs of impoverished chemically dependent women, is that substantial attention must be paid to the social context in which they live. Certainly, unhealthy family and community relationships can contribute to the problem of substance abuse, but effective responses are unlikely unless they, too, are built out of the web of affiliations that surround each individual.

Professor White concludes her article by suggesting that, in addition to the self-defeating coping strategies she found among her interviewees, they also, on occasion, demonstrated the ability to build organic groups within the social spaces created by Head Start. ${ }^{233}$ It is within these groups that the women of Head Start may undertake the difficult work of sharing, and responding to, their common experiences of subordination. This is not the mere telling of "war stories," but rather the beginning of a process of healing and empowerment in which participants explore the social world they inhabit, ${ }^{234}$ including not only the anxieties and degrada-

232. Id. at 1997.

233. Id. at 2001.

234. In some important respects this group work is akin to what feminist writers describe as "consciousness-raising." See generally Leslie Bender, A Lawyer's Primer on Feminist Theory and Tort, $38 \mathrm{~J}$. Legal EDUC. 3, 9 (1988) ("What were experienced as personal hurts individually suffered reveal themselves as a collective experience of oppression."); Catharine MacKinnon, Feminist Discourse, Moral Values and the Law - A Conversation, 34 BufF. L. REv. 11, 85-91 (1985) (consciousness-raising helps "women experienc[e] the walls that have contained them as walls"); see also supra note 208.

A key element in these feminist accounts, and equally important to the suggestion in text that Head Start may offer a site for similar work on the part of chemically dependent parents, is the notion that discovering common experience can often help participants.to begin a more affirmative course of conduct. As Christine Littleton has put it:

Shared experience, the substance of which consciousness raising is the method, is more than the aggregate of individual experiences, different in kind from their overlap. There is, in addition to the recognition of diversity and regularity, the experience of shared experience. This second level, or meta-experience, is what constructs women as an oppositional class.

Christine Littleton, Feminist Jurisprudence: The Difference Method Makes, 41 STAN. L. REv. 751,784 (1989). Of course, other writers, most notably Angela Harris, have criticized these descriptions of feminist method on the grounds that they adopt an "essentialist view" of women, or a view that ascribes an essential meaning to gender that transcends other characteristics such as race, class, sexual orientation, and the like. See Angela Harris, Categorical Discourse and Dominance Theory, 5 BERKELEY WOMEN's L.J. 181 (1990). One need not, however, view the methodology of consciousness raising as necessarily essentialist. "Rather, through consciousness-raising practices ... and exclusion questions, a heterogeneous group of women may discover not only points of surprising commonality but a bundle of surprising 
tion of poverty, racism, and sexism, but also the self-destructive reactions produced by a life lived alone and in social isolation. ${ }^{235}$

The suggestion here is that a mechanical application of the confidentiality statutes and regulations to the Head Start setting, by wrapping individual parents in a legally constructed shroud of privacy, poses the danger of alienating those parents from the very resource that may be most effective in helping them grapple with their chemical dependency. That resource, of course, is the set of relationships that, taken together, make up each parent's community. The law governing this area, when interpreted in traditional terms, understands chemical dependency as a particularistic, individualized problem with little or no social dimension. As such, the law is designed to operate within an institutional setting that is also highly particular and individualized. On the other hand, at least some measure of the alcoholism and drug addiction present among Head Start families can be more productively understood as a problem that transcends the individual parent or staff member. More effective interventions may depend upon the adoption of methodologies that draw in a number of linked individuals. In light of these observations, a modification of the traditional approach to confidentiality may be in order.

There are, of course, significant dangers lurking within this proposed course. The decision to replace legal entitlement, individual consent, and contractual obligation with vulnerability, informality, and trust is an especially risky undertaking when participants have conflicting interests or unequal power. For example, an addicted parent's interest in retaining custody of her or his child may be in direct conflict with a Head Start teacher's interest in safeguarding that child's physical or emotional well-being in cases where neglect or abuse is suspected.

differences." Phyllis Goldfarb, A Theory-Practice Spiral: The Ethics of Feminism and Clinical Education, 75 MINN. L. REv. 1599, 1629 (1991) (citation omitted).

235. In Professor White's words, these women

find ways to come together, searching out spaces where they can let down their guard. In those fleeting social spaces, they rage about the binds they are caught in, and hold on to each other, and laugh. They begin to voice their hopes for themselves and their children, and to imagine the bold actions that might realize those dreams. But above all, it is in those spaces that poor women feel safe enough to remember - to name the shame and violence that they confront every day in the public world .... I have seen women create such space within the institutional interstices of the Head Start program. Through the force of their imagination, they have seen this program not as one more social service bureaucracy, but rather as an opportunity to make community among themselves. ... They have transformed the Head Start program into "homeplace," an institution in which they feel safe to speak out about their own experiences of pain.

White, supra note 12 , at 2001. 
As a number of feminist writers have shown, dominant actors can easily subvert informal decisional or dispute resolution processes when participants do not stand on an equal footing, and these informal processes can strengthen or perpetuate existing inequities. $^{236}$ While a liberal, rights-based approach may fail to take account of existing relationships, an unrestrained communitarian strategy does not allow for law's potential to foster individuals' sense of autonomy and control over their lives, and to help define healthy relationships between the individual and her community. ${ }^{237}$

In the end, neither a liberal legal approach nor an unrestrained communitarian alternative, taken alone, is likely to be satisfactory. While they may be in tension, autonomy and affiliation need not be treated as mutually exclusive. ${ }^{238}$ Indeed, it may be possible to devise a set of practical solutions in which the recognition of legal rights occurs pursuant to a dialogue between involved actors, and in which those holding legal entitlements and those owing legal responsibilities are defined expansively so that the underlying human context is maintained and reinforced. 239

\section{CONCLUSION}

In his work on the role of rights in the welfare bureaucracy, William Simon has suggested that social work theory as it developed in the first half of the twentieth century held out the promise of reconciling rights and relationships. ${ }^{240}$ Simon shows that theorists understood individual client autonomy to be a product of social interaction, so that effective social work practice required staff to engage with clients and assist them in identifying goals and developing strategies to meet those goals. 241 Simon explains that within this conception, legal rights need not function as "conversation

236. See Lisa G. Lerman, Mediation of Wife Abuse Cases: The Adverse Impact of Informal Dispute Resolution on Women, 7 HARv. WOMEN's L.J. 57 (1984); Janet Rifkin, Mediation from a Feminist Perspective: Promise and Problems, 2 LAW \& INEQUALITY 21 (1984); see also THE Polmics OF INFORMAL Justice (Richard Abel ed., 1982); Richard Abel, Informalism: A Tactical Equivalent to Law?, 19 Clearinghouse Rev. 375 (1985); William H. Simon, Legal Informality and Redistributive Politics, 19 Clearnnghouse Rev. 384 (1985).

237. Indeed, as Patricia Williams and other critical race theorists have shown, the rhetoric of individual legal entitlement has a special symbolic power in our culture that, for subordinate groups, has fueled political movements of considerable empowering potential. See Patricia Williams, Alchemical Notes: Reconstructing Ideals From Deconstructed Rights, 22 HARv. C.R.-C.L. L. REv. 401 (1987).

238. See Rhode, supra note 163, at 628.

239. See Handler, supra note 143 , at $1090-91$.

240. See Simon, supra note 159, at 14-17.

241. See id. at 17. 
trumps, ending conversations," 242 but may be "regenerative," by which he means that they can foster a dialogue regarding the client's needs and circumstances. ${ }^{243}$ As a result, Simon concludes that this process of asserting legal rights could serve to enhance a client's self-respect and dignity. ${ }^{244}$

Recognizing client autonomy as "a goal, rather than ... a premise"245 is a critical step in moving away from a dichotomized analysis in which individual legal entitlement is understood as incompatible with affiliation. Nevertheless, calibrating the tension between autonomy and relationship - between legal rights and engaged trust - requires the application of what Katharine Bartlett has called "practical reasoning." She describes the approach in the following terms:

Practical reasoning approaches problems not as dichotomized conflicts, but as dilemmas with multiple perspectives, contradictions, and inconsistencies. These dilemmas, ideally, do not call for the choice of one principle over another, but rather "imaginative integrations and reconciliations," which require attention to particular context. ${ }^{246}$

This practical approach allows those involved to build solutions with the assistance of legal prescription rather than according to the abstract application of preexisting, generalized rules. Because rules "represent accumulated past wisdom," and "check the inclination to be arbitrary ... "in situations in which bias and passion might distort judgment," "247 they have value within this process. Because past wisdom may reflect the norms of a community other than the one to which the rules are to be applied, however, Bartlett's practical reasoning demands that "perspectives not represented in the dominant culture" be identified so that the rules can be reconfigured to serve the needs of those whose interests are at stake. ${ }^{248}$ This acknowledgement of the partial, contested nature of legal perspectives then opens up the possibility that law can be applied to people without transforming them into fully abstracted legal subjects.

242. Id. at 15; see also Handler, supra note 143, at 1096.

243. Simon, supra note 159 , at 16-17.

244. "Teaching the [welfare] claimant to regard herself as a right-holder was a means of enhancing her self-confidence and dignity." Id. at 20.

245. Id. at 16.

246. Bartlett, supra note 208, at 851 (citation omitted).

247. Id. at 852-53 (quoting Martha NusSbaum, ThE Fragiluty of GoodNESS: LuCK ANd Ethics IN Greek TRAgedy aNd PhILOSOPhy 305 (1986)).

248. Id. at 855 . 
With respect to the application of the federal confidentiality laws and regulations to Head Start, this process of tailoring legal prescriptions may require that the law regard families, rather than individual parents, as rights-holders, and that it understand a "program" to include the recipients of services as well as those providing those services. In many instances, the responsibility to protect the privacy of parents suffering from addiction or alcoholism may fall as heavily upon other parents as it does upon paid staff. Depending on the particular history and experiences of those involved . in the activities of any given Head Start center, the use of formal rights and full due process may serve to reinforce this shared responsibility, or it may undermine it.

The important point, however, is that each Head Start center will be different. Introducing formal legal rights to confidentiality, and making the application of those rights a part of the ongoing dialogue within a given community in order to foster both individual autonomy and a sense of responsibility for others is essential. Heeding the feminist directive to engage in contextual decisionmaking will mean confronting the tensions inherent in this effort, and will require legal doctrine to be reconceived in the light of specific, concrete local cultures. Each center must find a different accommodation between preexisting practices and the strictures set out in the federal laws and regulations. This is a process that can only be accomplished in the hundreds of church basements and school auditoriums in which the hard and important work of Head Start takes place. 